\title{
LAS CORTES DE FRANCO O EL PARLAMENTO IMPOSIBLE
}

\author{
Miguel ÁNGEL GiMÉNEZ MARTíNEZ \\ UNiversidad de CASTilla-La MaNCHA
}

\begin{abstract}
RESUMEN: La idea de que las Asambleas parlamentarias son órganos máximos del poder del Estado forma parte de la justificación teórica del Estado democrático de Derecho. Pero la existencia de una o varias Cámaras legislativas no implica que nos encontremos ante un Estado democrático, ni ante un Estado de Derecho. Un caso ejemplar es el de las Cortes puestas en marcha durante la dictadura de Franco, que no pueden ser consideradas como un verdadero Parlamento, aunque cumpliesen algunos cometidos de los mismos. No fueron una instancia de representación política, ni un Legislativo exclusivo y excluyente, ni un órgano del que emanase el Gobierno, ni un medio de control de la actuación gubernamental, y tampoco se constituyeron como una institución independiente, ya que en su funcionamiento dependía del Ejecutivo. ¿Qué fueron entonces las Cortes durante el franquismo? A esta pregunta trata de responder el presente artículo mediante la aplicación de una metodología multidisciplinar que combina la exégesis de los textos jurídicos, el análisis de la documentación archivística y el contraste con las aportaciones doctrinales.
\end{abstract}

PALABRAS CLAVE: España, dictadura de Franco, Cortes, Parlamento.

\section{THE FRANCO'S CORTES OR THE IMPOSSIBLE PARLIAMENT}

\begin{abstract}
The idea that parliamentary assemblies are supreme organs of state power is part of the theoretical justification of the democratic rule of law. But the existence on one or several legislative chambers does not imply that we are in the presence of a democratic state. A good example is the so-called Cortes implemented during Franco's dictatorship, which can not be considered as a true Parliament, although they accomplished some of their commitments. They were not a stage of political representation, or an exclusive legislative, or an organ from which the government originated, or a mean of control of the government action, and they were neither an independent institution, because its functioning depended on the executive. What was the significance of the Cortes during francoism? The present article tries to answer this question by means of applying a multidisciplinary methodology that combines the exegesis of legal texts, the analysis of archive documents and the contrast with doctrinal contributions.
\end{abstract}

KEYWORDS: Spain, Franco's dictatorship, Cortes, Parliament.

Recibido: 09-12-2014 /Aceptado: 23-07-2015

Trocadero, $\mathrm{n}^{\mathrm{o}} 27$ (2015), ISSN 0214-4212, pp. 67-100 
La configuración institucional de las Cortes durante el franquismo ofrece un ejemplo paradigmático de la escasa consistencia funcional de las estructuras que, con un pretendido carácter representativo, operan dentro de un régimen político autoritario ${ }^{1}$. Aunque la mayoría de los obstáculos que podían existir para la eficaz transmisión de la voluntad de Franco y los instrumentos de fiscalización fueron directamente suprimidos, otros fueron mantenidos por el negativo efecto de legitimación que habría causado su desaparición, condicionamiento este último que se encuentra latente en el caso de las Cortes por cuanto su existencia era una constante desde el nacimiento del Estado moderno ${ }^{2}$. A pesar de su mantenimiento, las Cortes retrocedieron gran parte del camino avanzado durante las etapas constitucionales anteriores al concebirse como una simple Cámara en la que encontrarían resonancia las decisiones de otras autoridades, debilidad que se hallaba en íntima relación con el carácter escasamente representativo de los cauces a través de los cuales se elegían a sus miembros ${ }^{3}$.

La creación de las Cortes, aun debilitadas al insertarse en un régimen marcadamente autoritario, debe enmarcarse necesariamente en el lento proceso institucionalizador a que debió someterse el Estado franquista una vez superados los momentos inmediatamente posteriores a la Guerra Civil. A pesar del intenso protagonismo que habría de conservar la Jefatura del Estado hasta el declive físico de Franco, el normal desenvolvimiento de las tareas políticas y administrativas no podía articularse en torno a la exclusiva dependencia de una sola persona, no solo por elementales razones de eficacia sino, sobre todo, por la exhaustiva función de control que exige el ejercicio totalitario del poder en todos los sectores. Resultaba preciso, por tanto, articular mecanismos que permitieran prolongar el poder supremo del Jefe del Estado más allá del campo de su autoridad directa, requerimiento que condicionaría la posterior evolución hacia la participación de un mayor número de órganos en el ejercicio del poder público. Sin

\footnotetext{
1 Sobre la naturaleza del régimen de Franco son útiles, entre otros, los trabajos de LINZ, Juan José: “An authoritarian regime: Spain”, en Erik ALLARDT e Yrjö LITTUNEN (eds.), Cleavages, ideologies and party systems: contributions to comparative political sociology, Helsinki, The Academic Bookstore, 1964, pp. 291-341; VILAR, Sergio: La naturaleza del franquismo, Barcelona, Península, 1977; RAMÍREZ, Manuel: España 19391975. Régimen politico e ideología, Barcelona, Labor, 1978; CHUECA, Ricardo: El fascismo en los comienzos del régimen de Franco. Un estudio sobre FET-JONS, Madrid, Centro de Investigaciones Sociológicas, 1983; PAYNE, Stanley G.: El régimen de Franco, 1936-1975, Madrid, Alianza, 1987; MOLINERO, Carme e YSÀS, Pere: El règim franquista. Feixisme, modernització i consens, Vic, Eumo, 2003 ; SAZ, Ismael: Las caras del franquismo, Madrid, Marcial Pons, 2007; DI FEBO, Giuliana y JULIÁ, Santos: El franquismo. Una introducción, Madrid, Crítica, 2012, y GIMÉNEZ MARTÍNEZ, Miguel Ángel: El Estado franquista. Fundamentos ideológicos, bases legales y sistema institucional, Madrid, Centro de Estudios Políticos y Constitucionales, 2014.

2 DÍAZ-NOSTY, Bernardo: Las Cortes de Franco. 30 años orgánicos, Madrid, Dopesa, 1972, p. 25.

3 VALERO TORRIJOS, Julián: Los órganos colegiados. Análisis histórico de la colegialidad en la organización pública española y régimen jurídico-administrativo vigente, Madrid, Instituto Nacional de Administración Pública-Centro de Estudios Políticos y Constitucionales, 2002, p. 298.
} 
embargo, esta medida no suponía en realidad una efectiva merma de la máxima autoridad de Franco sino, antes bien, una mera asistencia para su puesta en práctica, sin que, desde el punto de vista formal, la inicial concentración de poderes a su favor fuera objeto de expresa rectificación ${ }^{4}$.

En consecuencia, las Cortes franquistas no fueron una Asamblea parlamentaria, aunque cumpliesen algunos cometidos propios de estas instituciones, sino un órgano de representación de la clase dirigente, que ni legislaba exclusiva y excluyentemente, ni controlaba de manera eficaz la actuación gubernamental. Tampoco eran un órgano del que emanase el Gobierno, y no constituyeron una institución independiente, ya que en su funcionamiento interno dependían del Ejecutivo. Las Cortes de la dictadura se convirtieron en una Cámara de apoyo político para la resolución de ciertas cuestiones de relevancia "constitucional", una "fachada" que trataba de aparentar una representatividad que nunca tuvieron ${ }^{5}$.

\section{ORÍGENES IDEOLÓGICOS Y NATURALEZA}

La formación de la Cámara no debe entenderse como una improvisación coyuntural derivada de la necesidad de la dictadura por mejorar su imagen, sino como el triunfo de una parte fundamental del legado ideológico de la derecha antiliberal y contrarrevolucionaria española. Las Cortes de este período significaron, así pues, la puesta en marcha de un modelo representativo radicalmente contrario al fundamento liberal y democrático predominante hasta la fecha, en el que se mezclarían elementos tradicionalistas y falangistas ${ }^{6}$.

La principal aportación teórica realizada por el tradicionalismo consistió en la actualización de los postulados de la representación orgánica de origen medieval. La filosofía política tradicionalista, desarrollada a lo largo del siglo XIX y el primer tercio del $\mathrm{XX}$, se basará en una concepción de la sociedad distinta a la entendida por los liberales, en virtud de la cual a la mera suma de los individuos se opondrán otras sociedades “autárquicas” en su interior y "jerarquizadas" entre ellas. Fue Juan Vázquez de Mella el que, dentro de esta corriente de pensamiento, logró establecer con más coherencia una

${ }^{4}$ FERNÁNDEZ-CARVAJAL, Rodrigo: La Constitución Española, Madrid, Editora Nacional, 1969, p. 66.

5 SOTO CARMONA, Álvaro: "De las Cortes orgánicas a las Cortes democráticas", en Manuel REDERO SAN ROMÁN (ed.), La transición a la democracia en España. Ayer, n 15, 1994, p. 126.

${ }^{6}$ GONZÁLEZ CUEVAS, Pedro Carlos: El pensamiento politico de la derecha española en el siglo XX. De la crisis de la Restauración al Estado de partidos (1898-2000), Madrid, Tecnos, 2005, pp. 46-47.

${ }^{7}$ GIL ROBLES, Enrique: Tratado de Derecho Político según los principios de la filosofía y el derecho cristianos (1899), vol. II, Madrid, Afrodisio Aguado, 1961, pp. 391 y ss. 
doctrina social orgánica que sirviera de cimiento para la representación política, influyendo enormemente en el carlismo, en el pensamiento de la derecha monárquica de los años treinta y en la compleja ideología del franquismo ${ }^{8}$. Su teoría del "sociedalismo jerárquico" partía de la existencia de una sociedad civil estratificada en "cuerpos intermedios" que constituían sujetos autónomos de representación política y disponían de una función determinada". Esta estructura daba lugar a la "constitución social", base para la "constitución política" que se sostenía en el poder soberano del rey y el "contrapeso" de las Cortes $^{10}$. Efectivamente, según el ideario tradicionalista, las Cortes no tienen un poder propio, sino auxiliar, pues aquél corresponde al rey y no tiene que compartirlo, ya que, por derecho divino, éste es único en la persona del monarca y perpetuo en su familia ${ }^{11}$.

El discurso más depurado dentro del campo tradicionalista, el que concretará la composición de las Cortes orgánicas con mayor exactitud, será el del jurista navarro Víctor Pradera, cuya influencia sobre la Cámara del franquismo será muy superior a la de otros publicistas. Discípulo de Vázquez de Mella y amigo personal de Franco, Pradera decantó la tradición del pensamiento reaccionario español y lo fundió con las corrientes ultranacionalistas reunidas por Charles Maurras en L'Action Française, trasunto de la revista Acción Española que durante la II República vehicularía las ideas reaccionarias ${ }^{12}$. En el Estado que defiende Pradera, la división de poderes no tiene cabida, pues todos emanan del rey, que es el verdadero soberano. Existe, sin embargo, una "coordinación de funciones" y las Cortes tienen en el entramado institucional un carácter "conciliador", “deliberan, discuten y contraponen entre sí, orgánicamente, los diversos puntos de vista", pero carecen de una autoridad específica y están subordinadas al Gobierno ${ }^{13}$.

Durante la II República, el tradicionalismo entró en contacto con el fascismo a través de Falange y, aunque ni mucho menos lo absorbió en el plano organizativo, sí logró neutralizar en gran medida sus aires totalitarios. De hecho, en lo referente a las Cortes orgánicas, ambas formaciones compartían el mismo objetivo contra el sufragio universal y los partidos políticos, si bien el argumentario de carlistas y falangistas era sustantivamente

\footnotetext{
8 ARÓSTEGUI, Julio, estudio preliminar a la selección de textos de VÁZZUEZ DE MELLA, Juan: Una antología politica, Oviedo, Junta General del Principado de Asturias, 1999, p. 13.

9 VÁZQUEZ DE MELLA, Juan: Discurso integro de "Los tres dogmas nacionales" pronunciado en el Teatro de la Zarzuela el día 31 de mayo de 1915, Madrid, Diana, 1941, p. 24.

${ }^{10}$ VÁZQUEZ DE MELLA, Juan: Obras Completas, vol. VII, Madrid, Subirana-Junta de Homenaje a Mella, 1932, p. 114.

${ }^{11}$ NOCEDAL, Ramón: "Manifestación hecha en Burgos por la prensa tradicionalista", en Obras Completas, vol. I, Madrid, Imprenta Fortanet, 1907, p. 53.

12 ANTÓN MELLÓN, Joan: Ideologias y movimientos politicos contemporáneos, $2^{\mathrm{a}}$ ed., Madrid, Tecnos, 2006, pp. 207-208.

${ }^{13}$ PRADERA LARUMBE, Víctor: Obras Completas, vol. I, Madrid, Instituto de Estudios Políticos, 1945, pp. 124 y 220.
} 
diferente. En efecto, el pensamiento falangista rechazaba el parlamentarismo como sistema representativo y como forma de gobierno. En su primera vertiente, criticaba a las Cortes por basarse en el esquema democrático y liberal de representación inorgánica y en la premisa de la discusión plural como presupuesto para alcanzar una ley que manifestase la voluntad general. En cuanto forma de gobierno, José Antonio Primo de Rivera consideraba que el parlamentarismo conducía a un predominio incondicionado de las Cortes, convirtiéndose de facto en una dictadura parlamentaria, tanto más nociva por cuanto sus decisiones basculaban sin rumbo, siempre a merced de los vientos electorales ${ }^{14}$.

Las Cortes así concebidas no respetaban ningún "valor", por más asentado que estuviese en la historia. El ejemplo de la Asamblea constituyente de 1931 demostraba este aserto, al haber barrido de un solo golpe la confesionalidad del Estado vigente durante siglos. Frente a todo ello, el falangismo ofrecía una "democracia orgánica" y la dictadura de un "jefe", símbolo de la unidad nacional. Basándose en la idea de "unidad de destino", que petrificaba el ordenamiento jurídico y frenaba cualquier aspiración de pluralismo político, Falange proponía la participación ciudadana en la vida política a través de las asociaciones naturales (familia, municipio y sindicato vertical). El extremo en el que diferían tradicionalistas y falangistas estaba en que los segundos no pretendían "purificar" la naturaleza de las Cortes liberales, sino más bien sustituirlas por el Partido único y sus órganos particulares, a través de los cuales se articularía la representación del pueblo ${ }^{15}$.

El pensamiento de Franco se encontraba abiertamente identificado con el organicismo de veta tradicionalista y falangista. Si, por un lado, rechazaba la democracia y cualquier suerte de parlamentarismo liberal ${ }^{16}$, por otro admiraba el modelo tradicionalautoritario de representación que había ensayado la Asamblea Nacional Consultiva de la dictadura de Miguel Primo de Rivera ${ }^{17}$. Ya en su primera alocución lanzada el 18 de julio de 1936 anunció que del régimen que saliera del golpe de Estado sabría "salvar del forzoso naufragio que sufrirían algunos ensayos legislativos, cuanto fuera compatible con la paz interior de España y su anhelada grandeza" ${ }^{\prime 18}$. No obstante, en principio Franco no concebía nada más allá de su propio poder personal y el equilibrio entre los distintos

\footnotetext{
14 PRIMO DE RIVERA, José Antonio: Escritos y discursos. Obras completas (1922-1936), vol. II, Madrid, Instituto de Estudios Políticos, 1976, p. 158.

15 BENEYTO PÉREZ, Juan: El nuevo Estado español. El régimen Nacionalsindicalista ante la tradición y los sistemas totalitarios, Madrid-Cádiz, Biblioteca Nueva, 1939, pp. 166-170.

16 PLATÓN, Miguel: Alfonso XIII: de Primo de Rivera a Franco. La tentación autoritaria de la Monarquía, Barcelona, Plaza \& Janés, 1998, pp. 531-532.

17 MORODO, Raúl: "La proyección constitucional de la dictadura: la Asamblea Nacional Consultiva", en Boletin Informativo de Ciencia Politica, $\mathrm{n}^{\circ} 13-14,1973$, p. 86.

${ }^{18}$ DÍEZ, José Emilio: Colección de proclamas y arengas del excelentísimo señor general don Francisco Franco, jefe del Estado y Generalísimo del Ejército salvador de España, Sevilla, Carmona, 1937, p. 30.
} 
grupos que le prestaban su apoyo, por lo que no se planteó como una prioridad la creación a corto plazo de un foro de carácter consultivo o legislativo. De hecho, cuando una de las cabezas más visibles del tradicionalismo, Manuel Fal Conde, envió a Franco en 1939 un escrito solicitándole unas Cortes "integradas por procuradores elegidos por sufragio orgánico, con mandato imperativo y sujetos a juicio de residencia"19, el "Caudillo" dio largas a la sugerencia. Solo cuando se hicieron patentes los primeros síntomas del cambio en el equilibrio internacional, debidos a la creciente fuerza de las potencias aliadas, Franco comprendió que su supervivencia y la de su régimen dependían de la creación de instituciones de carácter representativo que, al menos formalmente, alejaran al Estado de un contexto explícitamente fascista.

Así pues, las Cortes estuvieron en suspenso hasta el 17 de julio de 1942, fecha en la que se restableció un órgano con esta denominación ${ }^{20}$, aunque dotado de una composición y unas funciones distintas a las que había tenido desde los albores del constitucionalismo español. A diferencia de lo que había sostenido José Antonio, la dictadura franquista concibió las Cortes también como un instrumento de participación, acogiendo así parte de la ideología tradicionalista española. La reanudación de las Cortes se justificaba en la ventaja, para la cohesión del régimen, de que las distintas "familias" políticas estuviesen presentes en la elaboración de las leyes. Según señalaba el preámbulo de la Ley Constitutiva de las Cortes (LC), la institución "tanto por su nombre cuanto por su composición y atribuciones" venía a "reanudar gloriosas tradiciones españolas". Su primer presidente, el tradicionalista Esteban Bilbao, insistió en la raigambre histórica de la Cámara, apelando a la "constitución histórica" y señalando que las Cortes se denominarían "Españolas" para apuntalar la idea de unidad ${ }^{21}$. Incluso el propio Franco, en el discurso inaugural de marzo de 1943, acudiría al precedente retórico de las Cortes de Castilla ${ }^{22}$.

Ha llegado a afirmarse que la LC de 1942 hizo de las Cortes un órgano de "naturaleza jurídica borrosa" 23 , en tanto su formación respondía a un esquema tradicionalista en lo fundamental pero contaminado por el sistema representativo de Partido único fascista, debido a la presencia como procuradores natos de los consejeros nacionales del Movimiento. También se les ha atribuido un carácter intermedio entre un

\footnotetext{
${ }^{19}$ FAL CONDE, Manuel: "Bosquejo de la futura organización política española inspirada en los Principios Tradicionales. Representación elevada a su excelencia el Jefe del Estado en Burgos el 10 de marzo de 1939", en El Pensamiento Carlista sobre cuestiones de actualidad, Buenos Aires, Artes Gráficas, 1939, pp. 72-73.

${ }^{20}$ Boletín Oficial del Estado (BOE), $\mathrm{n}^{\mathrm{o}} 200$, de 19 de julio de 1942, pp. 5.301-5.303.

${ }^{21}$ Boletín Oficial de las Cortes Españolas (BOCE), $\mathrm{n}^{\circ} 1$, de 16 de marzo de 1943, p. 14.

22 BOCE, no ${ }^{\circ}$, de 17 de marzo de 1943, p. 21.

${ }^{23}$ FERNÁNDEZ-CARVAJAL, Rodrigo: La Constitución..., op. cit., p. 113.
} 
Parlamento y una Asamblea consultiva ${ }^{24}$. En este sentido, las Cortes eran un órgano político con una función y una autoridad propias, con un procedimiento específico de actuación, pero que no se correspondía con el tipo de Asamblea parlamentaria de cuyo seno emanan los Gobiernos. Aunque es difícil atribuir una única naturaleza a una institución que se desarrolló durante un período de tiempo tan dilatado, sí puede concluirse que la constante fundamental de las Cortes fue su carácter no democrático. Tanto la LC como los sucesivos Reglamentos de la Cámara (RC) de 1943, 1946, 1957, 1967 y 1971 respondieron a los más rancios principios de negación del parlamentarismo y el pluralismo político. Se argumentaba, sin embargo, que la naturaleza de las Cortes respondía a una "auténtica democracia” o "democracia orgánica", que pretendía ser yuxtaposición de "una idea de legitimidad democrática" sobre "un pensamiento de lo que en cierto modo podríamos llamar legitimidad aristocrática" ${ }^{25}$.

La "democracia orgánica" "26, sin embargo, despojada de los prejuicios ideológicos franquistas, solo podía ser encuadrada en la categoría de los regímenes autocráticos, si por tales entendemos aquellos en los que existe "un único detentador del poder cuya competencia abarca la función de tomar la decisión política fundamental, así como su ejecución, y que además está libre de cualquier control eficaz" ${ }^{27}$. El argumento "superador" de la representación orgánica frente a la demoliberal resultaba de todo punto falaz, pues intentando evitar la oposición al sistema y a los principios fundamentales del régimen, lo que la dictadura hacía era eliminar cualquier oposición al equipo ministerial y a las políticas del mismo. La supresión de la democracia “de los partidos" eliminaba, así pues, cualquier tipo de democracia "real" 28 .

La cuestión de la naturaleza de las Cortes y del carácter de la representación política durante el régimen de Franco adquiere una especial significación si se la analiza desde una perspectiva exterior, es decir, sobre el concepto que desde el extranjero se tenía de las mismas. El caso de Europa es especialmente revelador. Los Estados miembros del Mercado Común, al que España aspiraba a integrarse, elaboraron en 1962 una doctrina en el Parlamento europeo sobre la base del "Informe Birkelbach" cuyo contenido, en el

${ }^{24}$ FRAGA IRIBARNE, Manuel: El Reglamento de las Cortes Españolas, Madrid, Servicio de Información y Publicaciones de la Organización Sindical, 1959, p. 14.

${ }^{25}$ ZAFRA VALVERDE, José: Régimen político de España, Pamplona, Eunsa, 1973, pp. 163-164.

${ }^{26}$ Sobre la significación del concepto de "democracia orgánica", vid. VARELA SUANZES-CARPEGNA, Joaquín y FERNÁNDEZ SARASOLA, Ignacio: "Leyes fundamentales y democracia orgánica. Aproximación al ordenamiento jurídico-político franquista", en Federico FERNÁNDEZ-CREHUET LÓPEZ, y António Manuel HESPANHA, (eds.): Franquismus und Salazarismus. Legitimation durch Diktatur?, Frankfurt am Main, Klostermann, 2008, pp. 197-234.

${ }^{27}$ LOEWENSTEIN, Karl: Teoría de la Constitución (1959), Barcelona, Ariel, 1964, p. 73.

${ }^{28}$ FERRANDO BADÍA, Juan: Democracia frente a autocracia. Los tres grandes sistemas políticos: el democrático, el socialmarxista y el autoritario, Madrid, Tecnos, 1980, pp. 292 y ss. 
aspecto político, obligaba a que los Gobiernos de los países aspirantes gozasen previamente de legitimación democrática y los pueblos participasen en las decisiones, de forma directa o por medio de representantes elegidos libremente. Ni el Gobierno ni las Cortes franquistas cumplieron nunca con este requisito, por lo que España fue sistemáticamente excluida de esta organización ${ }^{29}$.

\section{COMPOSICIÓN}

La importancia y eficacia reales de la actividad parlamentaria estarían determinadas en gran medida por el sesgado carácter representativo de sus miembros, configuración que debe analizarse partiendo de las exigencias de control político que requirió la conservación de un Estado autoritario de corte personalista en el que las manifestaciones asamblearias constituían una de las fuentes principales de desintegración de la doctrina oficial. En perfecta coherencia con estos planteamientos, la LC de 1942 estableció una composición integradora de las diversas "familias" o corrientes oficiales del régimen, reservando un número importante de procuradores a la libre elección por el Jefe del Estado ${ }^{30}$. Así, la docilidad de la institución se aseguraba al reunir junto a distinguidos miembros de las estructuras administrativas estatal y local a relevantes personalidades del Partido único y representantes de diversas corporaciones profesionales, de manera que la potencial fortaleza del órgano quedaba debilitada por el control gubernamental, bien a través de la designación de los cargos principales que daban acceso a las Cortes a sus titulares, bien en virtud de la elección directa por Franco ${ }^{31}$. El carácter oficialista de la composición se percibe claramente al observar el listado recogido en la LC. Eran procuradores los ministros del Gobierno; los consejeros nacionales del Movimiento; los presidentes de los Altos Órganos consultivos y del Tribunal Supremo; los representantes de la Organización Sindical hasta completar un tercio de la Cámara; los alcaldes de las capitales de provincia y un representante de los restantes municipios por cada una de ellas; los rectores universitarios; los presidentes de las Reales Academias; los representantes de los Colegios Oficiales de Abogados, Médicos, Farmacéuticos, Veterinarios y Arquitectos elegidos

\footnotetext{
29 TAMAMES, Ramón: La larga marcha de España a la Unión Europea: un futuro para el desarrollo, Madrid, Edimadoz, 1999, p. 133.

${ }^{30}$ LISSARRAGUE NOVOA, Salvador: "La Ley creadora de las Cortes", en Revista de Trabajo, no 33, 1942, p. 256.

31 BAÑÓN MARTÍNEZ, Rafael: Poder de la burocracia y Cortes franquistas, 1943-71, Madrid, Instituto Nacional de Administración Pública, 1978, p. 167.
} 
directamente por el decano o el presidente respectivo; y 50 procuradores libremente designados por el Jefe del Estado ${ }^{32}$.

Esta composición sería ligeramente modificada en 1946, si bien la reforma estaría inspirada por los mismos principios antes referidos y se limitaría a intensificar el carácter representativo de los designados con relación a las instituciones a quienes correspondía su elección. Así, los representantes de los municipios pasaron a ser elegidos por los propios municipios y no por la respectiva Diputación Provincial, si bien éstas últimas también consiguieron acceder a las Cortes por medio de sus presidentes, que se convirtieron en procuradores natos. En el mismo sentido, los representantes de las Reales Academias habían de ser elegidos desde esta fecha por sus miembros y los de los Colegios profesionales por la propia directiva, de manera que se ampliaba tímidamente este limitado sufragio activo antes en poder de órganos unipersonales ${ }^{33}$.

Mayor importancia debe concederse a la ampliación operada en 1967 por la Ley Orgánica del Estado $(\mathrm{LOE})^{34}$, por cuanto extendía la composición de las Cortes para dar cabida a "dos representantes de la familia por cada provincia, elegidos por quienes figuren en el censo electoral de cabezas de familia y mujeres casadas" ${ }^{35}$. Lo que aparentemente se supuso expresión parlamentaria de uno de los tres tipos de unidades sociales "naturales", fue en realidad una concesión a la representación política de base individual. De hecho, las dos elecciones al tercio familiar de las Cortes, que se celebraron en octubre de $1967 \mathrm{y}$ septiembre de 1971, supusieron el momento de mayor animación política durante el período de vigencia del régimen de Franco, acostumbrado a promover la desmovilización y el apoliticismo entre los españoles. El dictador, tan contrario durante toda su vida a la expresión de la voluntad de los ciudadanos por medio del "acto de depositar un papelito en una urna" ${ }^{36}$, cedió en este punto a las presiones de los aperturistas, que querían abrir el régimen a alguna forma de participación individual, completando así, de una manera imprecisa, la democracia orgánica con ciertos mecanismos de la democracia liberal.

Una clase política joven que estaría llamada a ocupar puestos de relevancia durante la transición a la democracia consiguió sus primeros cargos de responsabilidad gracias a las elecciones por el tercio familiar. Así, entre los que obtuvieron escaños se encontraban, entre otros, Adolfo Suárez (Ávila), María Belén Landáburu (Burgos), Josep

\footnotetext{
${ }^{32} L C$, art. 2.

${ }_{33}$ BOE, no 199 , de 18 de julio de 1946, pp. 5.655-5.656.

${ }^{34}$ FERNÁNDEZ-CARVAJAL, Rodrigo: “Las Cortes Españolas en la Ley Orgánica del Estado”, en Revista de Estudios Políticos, no 152, marzo-abril de 1967, pp. 72 y ss.

${ }^{35}$ Ley de Representación Familiar en Cortes (LRFC), preámbulo. Vid. BOE, no 156, de 1 de julio de 1967, pp. 9.181-9.182.

36 BOCE, no 151 , de 14 de mayo de 1946, p. 2.979.
} 
Melià (Baleares), Pío Cabanillas (Pontevedra), Alfonso Osorio (Santander), Fernando Abril Martorell (Segovia) o Enrique de la Mata (Teruel). Los procuradores familiares gozaron de una legitimidad muy superior a la de sus compañeros, pues su cargo no se debía a un nombramiento más o menos "a dedo", sino a un apoyo directo expresado en las urnas por parte de los ciudadanos. Este mayor respaldo se tradujo en una actividad mucho más intensa por su parte, ya fuera formulando ruegos y preguntas, solicitando comparecencias ministeriales, interpelando al Gobierno, elaborando proposiciones de ley o rindiendo cuentas de su gestión a través de artículos y cartas publicadas en la prensa. La función crítica ejercida por algunos de estos procuradores les llevaría incluso a poner en entredicho públicamente la independencia de las Cortes y calificarlas de mera "caja de resonancia de las decisiones tomadas por el Ejecutivo" ${ }^{37}$, si bien estas actitudes suponían el fin inmediato de la carrera parlamentaria del implicado.

Diversos obstáculos, sin embargo, provocaron que la acción de los procuradores familiares se viera aislada, entorpecida $y$, en último término, fracasara como verdadera avanzadilla para una ulterior democratización del régimen. Las limitaciones de su labor se percibieron desde el primer momento por el incumplimiento de unos programas que, ya de por sí, eran bastante imprecisos y redundaban en cuestiones como la vinculación local, la ascendencia humilde o las declaraciones de amor y conocimiento de la tierra natal ${ }^{38}$. La militancia de los procuradores familiares era, por otro lado, abiertamente franquista, más allá de la superficial y vacilante competencia entre candidaturas "oficiales" cercanas al Movimiento e "independientes", por lo que no se podía esperar de ellos un enfrentamiento con el poder desde las instituciones: a pesar de las múltiples iniciativas parlamentarias que protagonizaron, su actitud respecto al Gobierno siguió siendo de una sumisión similar a la del resto de miembros de la Cámara ${ }^{39}$. Pronto se observó, además, que, a pesar de la apertura que supusieron las elecciones, habían ganado "los de siempre", pues aunque algún cargo de la Administración fue derrotado, 2 de cada 3 de los "nuevos" procuradores lo habían sido ya en las legislaturas anteriores. Reprimidos los llamados "trashumantes", grupos de procuradores críticos que se reunían en distintos puntos del país con gran expectación de la prensa, no volvieron a intentarse actividades de este tenor y, lo que fue más grave para la evolución del sistema, el autoritarismo del Gobierno cerró uno de los

\footnotetext{
${ }^{37}$ LUACES SAAVEDRA, Joaquín: "La independencia de los procuradores", en El Norte de Castilla, de 16 de noviembre de 1968.

38 AGUILAR TREMOYA, Miguel Ángel: Las últimas Cortes del franquismo, Madrid, Avance, 1976, p. 89.

39 VANACLOCHA BELLVER, Francisco José: "Las elecciones de representación familiar en las Cortes Españolas (1967-1974) como elecciones no competitivas", en Cuadernos Económicos de Información Comercial Española, $\mathrm{n}^{\circ} 1,1977$, pp. 59-76.
} 
cauces de apertura que más creíbles habían resultado. Lo que, de haber persistido, pudo haber sido "un fenómeno renovador de incalculables posibilidades y un contrapeso frente a los procuradores sumisos" quedó cortado de raíz y produjo "un menosprecio de la institución parlamentaria" que se prolongó hasta la extinción de la Cámara ${ }^{40}$.

Si nos atenemos a la composición individual de los representantes de las Cortes franquistas hemos de llegar a la primera conclusión de que éstas constituyeron un mosaico de incalculable valor para comprender la variedad de "familias" políticas que habitaban en el seno de la dictadura. Los procuradores que se dieron cita en la Cámara tenían un origen dispar: falangistas, católicos, tradicionalistas, monárquicos y tecnócratas se repartieron los escaños representando fielmente el esquema de poder del régimen ${ }^{41}$. Aunque sin duda hubo tensiones y diferencias entre estos procuradores, como entre los grupos que representaban, los conflictos quedaban muchas veces anulados por la comunidad de intereses $y$, sobre todo, por la disciplina interna, vigilada en todo momento por la mano del dictador a través de la Presidencia de la Cámara.

Una somera impresión visual de las Cortes evidencia el predominio del elemento falangista en la Cámara. En las sesiones inaugurales de las legislaturas predominan claramente las camisas azules y las chaquetas blancas del Movimiento, reservadas para los actos oficiales de gala. No en vano, de los 2.551 procuradores, 1.182 fueron falangistas, es decir, el 46,7\% del total. Su número es constante a lo largo de las legislaturas, si bien con las reformas introducidas por la LOE y el desembarco de los tecnócratas redujeron su peso relativo en el Cuerpo legislativo. La presencia de falangistas estaba garantizada por los puestos reservados a la Organización Sindical, dominada por el Movimiento, y por la condición de procuradores natos que ostentaban los consejeros nacionales. A ello hay que añadir los esfuerzos económicos del Partido único por colocar a sus candidatos en las elecciones familiares, donde en muchos casos pugnaban con éxito frente a los demás candidatos, independientes o de otras corrientes del régimen.

El segundo grupo por su importancia numérica es el de los tecnócratas. Su aparición es más tardía, pero fue creciendo hasta convertirse en mayoritaria a partir de 1967. A los tecnócratas se les reconoce "por descarte": eran católicos (generalmente, aunque no siempre, del Opus Deı), pero no falangistas, no militares, no monárquicos, no tradicionalistas y no "de la santa casa". Representaban "una perfecta mixtura entre

\footnotetext{
40 CLEMENTE, José Carlos: Conversaciones sobre el presente y el futuro político de España, Barcelona, Editorial Juventud, 1972, p. 56.

41 JEREZ MIR, Miguel: Élites políticas y centros de extracción en España, 1938-1957, Madrid, Centro de Investigaciones Sociológicas, 1982.
} 
liberalidad económica y autoritarismo político" ${ }^{42}$, es decir, la fórmula predominante en la España del desarrollismo. Hubo 830 procuradores que se ceñían a esta caracterización, lo que representaba el 32,5\% del conjunto.

La familia católica, entendida ésta como la de los políticos cercanos al núcleo de la Asociación Católica Nacional de Propagandistas (ACN de P), Acción Católica y Editorial Católica (diario Ya), ocupaba un puesto más modesto en las Cortes (118 procuradores, un 4,6\%) pero cualitativamente desplegaban un importante papel al estar adscritos a lugares clave de la cultura. Así, hacia 1960, la gran mayoría de los catedráticos de Universidad eran "personalmente católicos militantes o activos o, por lo menos, se conducían socialmente como tales" ${ }^{43}$. Llevaban a la Cámara la voz de la Iglesia y trasmitían la ideología, tan pragmática como reaccionaria, de que la legislación no debía despegarse de la religión.

Los monárquicos, por su parte, actuaban enfrentándose a los falangistas por sus devaneos "republicanos" o "regencialistas", moviéndose ambivalentemente entre la fidelidad emotiva hacia don Juan de Borbón y el acatamiento del orden interior existente. Su número, mermado en conjunto (42 procuradores, el 1,6\%), era mucho mayor durante las primeras legislaturas y fue decreciendo con el paso de los años. Sufrieron, además, las consecuencias de la carta remitida en 1943 por un buen número de ellos, en la que solicitaban a Franco la restauración de la monarquía en España en la persona del conde de Barcelona. La reacción del régimen fue drástica: multas, confinamientos y destituciones de sus puestos para todos los implicados ${ }^{44}$.

Por último hemos de hacer referencia al grupo tradicionalista, inspirador ideológico de los elementos fundamentales de las Cortes, la "familia" más homogénea de todas las de la dictadura. Hay que hacer notar, sin embargo, el predominio de los "carlistas domesticados", es decir, aquellos que aceptaban o toleraban la decisión de Franco en la cuestión sucesoria y aparcaban la exigencia de entronizar de nuevo a la rama "legítima". Funcionaron -igual que los católicos- como valladar ideológico para impedir que el régimen se convirtiera en un sistema de tipo fascista, en permanente pugna con los falangistas. El tándem Bilbao-Iturmendi que, como veremos, estuvo casi treinta años al frente de las Cortes, garantizó el éxito de este cometido. Hubo un total de 79 tradicionalistas en la Cámara, un 3\% del total.

42 DE MIGUEL, Amando: Sociología del Franquismo. Análisis ideológico de los ministros del Régimen, Barcelona, Euros, 1975, p. 223.

43 Ibidem, p. 205.

${ }^{44}$ SÁINZ RODRIGUEZ, Pedro: Un reinado en la sombra, Barcelona, Planeta, 1981, pp. 123-126. 
En cuanto a su estatus jurídico, los procuradores en Cortes, como especiales gestores y funcionarios públicos, tenían una consideración semejante a la de los parlamentarios de cualquier otro país. Mientras la inmunidad estaba recogida en la LC, la inviolabilidad no estuvo regulada de forma convencional hasta 1957. Así, los miembros de la Cámara no podían ser detenidos sin autorización previa del presidente de las Cortes salvo en caso de flagrante delito ${ }^{45}$. Sin embargo, la práctica de este derecho de inmunidad creó un "campo de impunidad" 46 para los procuradores. Amparándose en la levedad de las faltas, se denegaron la gran mayoría de los 39 suplicatorios que fueron solicitados a la Cámara, al aducirse que "no se lleva cuenta de la dignidad, profesión o empleo de los distintos señores procuradores". Así, quedaron impunes hechos relativos a "apropiación indebida y hurto", "apropiación ilegal", "robo", "coacción", "golpear a su mujer", "increpar a un guardia", o "falsedad documental" 47 . La arbitrariedad fue tal que incluso "a un gobernador civil que fue objeto de denuncia por torturas y sevicias [...] se le hizo procurador para que gozase del privilegio de inmunidad" 48 .

\section{FACULTADES}

Partiendo de la fragilidad que otorgaba a las Cortes su íntima conexión y dependencia con los principios ideológicos del régimen, las funciones que habrían de asumir distarían de alcanzar la importancia característica de los Parlamentos democráticos. La efímera función de control político que se había consolidado en algunos momentos de la etapa constitucional y, en concreto, bajo el modelo republicano inaugurado en 1931, donde se preveía expresamente el voto de censura frente al Gobierno ${ }^{49}$, quedaría anulada por cuanto su ejercicio correspondía exclusivamente al Jefe del Estado, ante quien respondían directamente los miembros del Gobierno por las decisiones que adoptaban. No obstante, al menos de forma aparente, los sucesivos Reglamentos de las Cortes previeron en su articulado ciertos mecanismos que permitían ejercer sobre el Ejecutivo una relativa actividad fiscalizadora, si bien la realidad de los hechos se encargaría de demostrar su

\footnotetext{
45 FRAGA IRIBARNE, Manuel: "Los privilegios de los procuradores y el nuevo Reglamento de las Cortes Españolas", en Revista de Estudios Políticos, no 99, mayo-junio de 1958, p. 57.

46 FERNÁNDEZ-MIRANDA CAMPOAMOR, Alfonso: "La inmunidad parlamentaria en la práctica de la II República y de las Cortes Orgánicas”, en Revista Española de Opinión Pública, no 49, julio-septiembre de 1977, p. 148.

47 Archivo del Congreso de los Diputados (ACD), serie general, caja 1.451, carpetas 22, 41, 47, 59, 73,77 y 85.

48 CARRO MARTÍNEZ, Antonio: "La inmunidad parlamentaria", en Revista de Derecho Político de la Universidad Nacional de Educación a Distancia, no 9, primavera de 1981, p. 104.

49 Constitución de la República Española, art. 64. Vid. Gaceta de Madrid, n 344, de 10 de diciembre de 1931, p. 1.583 .
} 
limitada eficacia práctica, pues solo en contadas ocasiones lograron alcanzar el resultado pretendido.

El RC de 1946 admitió la posibilidad de que los procuradores pudieran formular ruegos y preguntas al Gobierno, los cuales simplemente provocaron, o aceleraron, la respuesta favorable a cuestiones en que previamente la Administración ya había decidido actuar, sirvieron de caja de resonancia para presionar sobre temas que estaban en otros canales, o consiguieron impulsar y promover la acción del Gobierno en algún caso muy concreto y acotado, de fácil concesión o evidente necesidad. Los límites a la técnica de control de los ruegos y preguntas vinieron dados por los condicionamientos impuestos por la propia estructura normativa y por la nula voluntad del Gabinete en colaborar. Así, la tramitación de las cuestiones tenía que hacerse, necesariamente, por escrito en el Boletín Oficial de las Cortes, lo que les restaba una gran publicidad, sobre todo porque no suscitaban un debate posterior con motivo de su contestación ${ }^{50}$. El Ejecutivo, por su parte, además del recurso de retrasar las respuestas o, simplemente, de no contestar, podía emplear evasivas: lo que algún procurador denominó "método Ollendorf”, es decir, "contestar lo que a uno le apetece y no lo que le preguntan" 51 . Los ruegos y preguntas fueron, en definitiva, un "mal menor" controlador que el régimen toleró dentro de su contexto autoritario, sin provocar una eclosión tal de sus contradicciones que acabara impidiendo prácticamente su viabilidad y cuestionando su coexistencia con las demás piezas del sistema. Las magnitudes de la Cámara franquista no resistían la menor comparación con otros Parlamentos democráticos de la época: mientras entre 1968 y 1972 la Asamblea Nacional francesa y la Cámara de los Diputados italiana recibían más de 32.000 questions écrites y 22.000 interrogazioni, las Cortes Españolas solo conocieron 438 ruegos 52 .

Respecto del instrumento más contundente de las interpelaciones, introducido en el RC de 1957, éstas se hacían siempre oralmente y ante el Pleno de las Cortes o la Comisión correspondiente, según la naturaleza e importancia del tema. A ellas contestaba un ministro que en cada caso decidiera el Gobierno. Una vez aceptada la interpelación e incluida en el orden del día, su autor podía exponerla en la sesión durante un tiempo no superior a media hora. Tras la contestación del ministro podía el interpelante "rectificar" en un máximo de 10 minutos, lo cual permitía al miembro del Gobierno intervenir finalmente

${ }^{50}$ IGLESIAS SELGAS, Carlos: La vía española a la democracia, Madrid, Ediciones del Movimiento, 1968, pp. 170-171.

51 BOCE, Diario de las Sesiones de las Comisiones (DSC), no 267, de 6 de noviembre de 1971, p. 19.

52 GARRORENA MORALES, Ángel: Autoritarismo y control parlamentario en las Cortes de Franco, Murcia, Departamento de Derecho Político de la Universidad de Murcia, 1977, p. 74. 
si lo solicitaba. Con ello terminaba el trámite, pues, además de no preverse legalmente la posibilidad de un debate más amplio, estaba taxativamente prohibido que se votara sobre la cuestión $^{53}$. De este modo, las interpelaciones quedaban privadas de sus sustantivas consecuencias procedimentales y se convirtieron en instrumento inútil y poco empleado, un mero "recurso semántico", una "interpelación sin interpelación" ${ }^{4}$. Solo se depositaron 2 en las primeras ocho legislaturas (1943-1967), al ministro de Obras Públicas sobre la situación de las carreteras españolas, y al de Agricultura sobre la política del departamento de su competencia. La utilidad de las interpelaciones era, en realidad, más sutil y se relacionaba con la mejora de la carrera política personal del interpelante. Así, las Cortes actuaban como cantera de futuros subsecretarios o ministros, puesto que la "brillantez parlamentaria" favorecía el ascenso dentro de la Administración ${ }^{55}$.

Otro mecanismo de control parlamentario puesto a disposición de las Cortes era el de las sesiones informativas, aparecidas normativamente como consecuencia de la reforma del RC de 1971, si bien su uso se inició en 1968. Tenía por finalidad ofrecer a los ministros la posibilidad de informar regularmente ante la Comisión correspondiente de la actividad general de su departamento. Se celebraron en total 42 sesiones de estas características, pero más allá de las múltiples rectificaciones que se arbitraron (agrupación de cuestiones por temas, sistema de portavoces, sesiones monográficas, eliminación de cuestiones localistas, límites temporales a las intervenciones, etc.) para permitir una mayor fluidez en las preguntas y respuestas de los procuradores y los ministros, el marco autoritario en el que estas sesiones quedaron insertas impidió que esta modalidad de fiscalización fuera realmente eficaz ${ }^{56}$.

Y ello porque los ministros tenían a su disposición múltiples artimañas para evitar que los ruegos de los procuradores les desgastaran siquiera mínimamente. En primer lugar, nada obligaba a un ministro a acudir a estas sesiones y, cuando éste así lo decidía a su libre entender, establecía discrecionalmente la oportunidad y temática del encuentro. Una vez iniciado, el ministro podía arrancarse con un extenso discurso que se adelantase a las preguntas y, a continuación, agrupar las existentes diluyendo en una contestación global los

\footnotetext{
${ }^{53}$ MOLERO ALONSO, Diego: Las interpelaciones parlamentarias, Madrid, Congreso de los Diputados, 2003, p. 179.

${ }^{54}$ FRAILE CLIVILLÉS, Manuel María: Comentario al Reglamento de las Cortes, Madrid, Instituto de Estudios Políticos, 1973, p. 1.014.

${ }^{55}$ LÓPEZ RODÓ, Laureano: Memorias, Barcelona, Plaza \& Janés, 1990, pp. 535-536.

56 GIMÉNEZ MARTÍNEZ, Miguel Ángel: Las Cortes Españolas en el régimen de Franco. Nacimiento, desarrollo y extinción de una Cámara orgánica, Madrid, Congreso de los Diputados, 2012, p. 245.
} 
matices de las cuestiones concretas ${ }^{57}$. A todo ello se suma que los ministros, a fin de cuentas, sabían que las consecuencias de estas sesiones eran nulas, dado que el Pleno no les podía exigir después responsabilidad alguna.

Por último, dentro de las funciones de control atribuidas a las Cortes, hay que hacer referencia a las Comisiones especiales de encuesta, versión adaptada de las Comisiones de investigación de los regímenes democráticos. La visión que legalmente se tenía de ellas, totalmente rudimentaria, giraba sobre la idea de estudios documentales, pues no se preveía la posibilidad de interrogatorios. De esta fiscalización por encuestas únicamente existió un caso, el de la Comisión sobre el escándalo financiero Matesa. Varios procuradores pidieron durante el verano de 1969 un Pleno especial para dirimir responsabilidades al respecto, pero la Presidencia de la Cámara no aceptó en un principio ${ }^{58}$. Sin embargo, las insistentes presiones desde diversos ámbitos del régimen empujaron a la constitución de la referida Comisión, hecho insólito durante el franquismo que hay que enmarcar dentro de la pugna sostenida por aquel entonces entre "azules" y tecnócratas ${ }^{59}$. El dictamen final redactado por la Ponencia de la Comisión, bajo presiones del Gobierno, fue mantenido en sumo secreto, y su presentación ante el Pleno se realizó sin periodistas ni taquígrafos en su interior ${ }^{60}$. El espíritu del mismo constituía una "acusación global al régimen", tanto que, conforme se iban desgranando sus conclusiones, muchos procuradores "dieron rienda suelta a su indignación con sonoros pateos" específico del dictamen nunca llegó a conocerse en su integridad más allá de filtraciones periodísticas, y las peticiones y propuestas de reformas jurídicas realizadas por la Cámara, tendentes a establecer un mayor control sobre los créditos oficiales y un endurecimiento de las penas por estafa no fueron escuchadas. Al final, las Cortes se vieron humilladas e inoperantes en el "caso Matesa": el común compromiso de los jerarcas del régimen y las lealtades al sistema impidieron que la Cámara se pronunciase públicamente y ejerciese su labor.

\footnotetext{
${ }^{57}$ Ejemplo de este modo de proceder fue el ministro de Educación y Ciencia, José Luis Villar Palasí, que inició una sesión informativa con un discurso de casi hora y media y, a continuación, agrupó las preguntas de todos los procuradores, contestándolas en otra larga exposición de dos horas y media de duración. Vid. BOCE, DSC, no 10, de 14 de febrero de 1972, pp. 3-19 y 44-80.

${ }^{58}$ HISPÁN IGLESIAS DE USSEL, Pablo: La politica en el régimen de Franco entre 1957 y 1969. Proyectos, conflictos y luchas por el poder, Madrid, Centro de Estudios Políticos y Constitucionales, 2006, p. 595.

59 SOTO CARMONA, Álvaro: ¿Atado y bien atado? Institucionalización y crisis del franquismo, Madrid, Biblioteca Nueva, 2005, p. 100.

${ }^{60}$ BOCE, DSC, no 1, de 30 de junio de 1970, pp. 18 y ss.

${ }^{61}$ ROMERO, Emilio: Tragicomedia de España. Unas memorias sin contemplaciones, Barcelona, Planeta, 1985, p. 174.
} 
Por lo que respecta a la participación de las Cortes en el procedimiento de elaboración de las leyes, la regulación originaria de 1942 estaba condicionada por la atribución de la suprema potestad para dictar normas jurídicas de carácter general a favor del Jefe del Estado que realizaban las Leyes de 30 de enero de 1938 y 8 de agosto de 1939. De ahí que la Cámara debiera limitarse a un simple papel colaborador y preparatorio que, al menos materialmente, podría considerarse de naturaleza consultiva, si bien esta intervención desaparecía en los supuestos en que el Gobierno podía acudir directamente a la figura del decreto-ley. A pesar de que la LC efectuaba una reserva material en favor del Pleno $^{62}$, la expresión "preparación y elaboración de las leyes" a la que hacía referencia el artículo 1 de la misma Ley debe entenderse con la salvedad de la decisión final del Jefe del Estado $^{63}$, que en todo caso tenía reservada la sanción, hasta el punto de que podía "devolver las leyes a las Cortes para nuevo estudio" ${ }^{64}$. Con este alcance de simple colaboración en la redacción de los proyectos normativos hay que interpretar la locución "son competencia de las Comisiones de las Cortes todas las demás disposiciones que no estén comprendidas en el artículo décimo" ${ }^{65}$. Ahora bien, "en los supuestos de guerra o por razones de urgencia", el Gobierno podía regular estas materias por decreto-ley dando simplemente cuenta a las Cortes posteriormente, obligación que desaparecería tras la reforma de 1946. Lo cierto es que el instrumento de los decretos-leyes se empleó la mayor parte de las veces para asuntos que no tenían urgencia alguna, por lo que la Cámara sufriría una variable pero constante dosis de ninguneo que desprestigiaba su labor legislativa y la subyugaba a la voluntad del Gobierno ${ }^{66}$. La naturaleza de la intervención de las Cortes era matizadamente distinta en el caso de que se tratara de una de las Leyes Fundamentales enumeradas por la Ley de Sucesión en la Jefatura del Estado (LSJE), precepto que exigía "para derogarlas o modificarlas [...] además del acuerdo de las Cortes, el referéndum de la nación" ${ }^{67}$. Se trataba de un supuesto excepcional previsto con una evidente función protectora, a fin de impedir mutaciones esenciales del régimen en manos de un futuro Jefe del Estado.

Mayores son, por el contrario, las funciones que asumirían tras las importantes reformas acaecidas en 1967, momento a partir del cual las Cortes no se limitarán simplemente a elaborar las leyes sino que, además, les corresponderá su aprobación, sin

\footnotetext{
${ }^{62} \mathrm{LC}$, art. 10.

${ }^{63} \mathrm{LOE}$, art. 16.

${ }^{64} \mathrm{LOE}$, art. 17.

${ }^{65} \mathrm{LOE}$, art. 12.

${ }^{66}$ SALAS, Javier: "Los decretos-leyes en el ordenamiento jurídico español. En torno a la urgencia”, en Revista de Administración Pública, no 51, 1966, pp. 41 y ss.

${ }^{67}$ LSJE, art. 10.
} 
perjuicio de que la sanción siguiera correspondiendo a Franco, si bien esta facultad ya no se concebía con la misma amplitud al exigirse una decisión motivada y el correspondiente dictamen preceptivo del Consejo del Reino antes de devolver el texto a las Cortes para una nueva deliberación. El "Caudillo" gozaba, pues, de un "veto resolutorio" más propio de las Monarquías limitadas que de los regímenes constitucionales políticamente avanzados, en los que los Jefes de Estado disfrutan de un "veto suspensivo". Por consiguiente, desde esta perspectiva habría que considerar la ley como un "acto complejo" del Jefe del Estado y de las Cortes, dado que la sanción de la misma por aquél tenía igual valor y eficacia, si no más, que la aprobación por las mismas Cortes de un proyecto o proposición de ley ${ }^{68}$. En coherencia con el fortalecimiento parlamentario referido, los supuestos y condiciones en que el Gobierno podía hacer uso de los decretos-leyes se limitaron para garantizar el normal ejercicio de la potestad legislativa por su titular.

No obstante, hay que recordar una vez más que mientras no se produjo la sucesión en la Jefatura del Estado, Franco conservó intactas sus competencias normativas establecidas en las ya citadas Leyes de 1938 y 1939, confirmadas por la LOE, a pesar de lo cual su comportamiento se sujetó en la práctica a la nueva regulación ante la plena conciencia del carácter sumiso de las Cortes. Y es que, de los 4.415 dictámenes emitidos por las Comisiones en el período 1943-1967, el Pleno de las Cortes votó solo 340 de ellos, de modo que los restantes eran simplemente leídos y se tenían por aprobados con ese solo procedimiento. De los pasados a votación, 139 (el 41\%) salieron adelante sin consignación alguna de resultados o "por asentimiento". En otros casos, 97 (el 29\%), sí se procedió al recuento, y el resultado fue unánime a favor del dictamen. Las oposiciones eran algo excepcional en la Cámara: en 60 ocasiones se consignaron menos de 5 votos contrarios, en 25 se contaron entre 5 y 15 , y solo en 19 dictámenes se pudieron encontrar más de 15 procuradores opuestos a una ley proyectada por el Gobierno. Ni que decir tiene que nunca en la historia de las Cortes se produjo una sola votación adversa al Gabinete. A la vista de estos datos se comprende que la Cámara no fue nunca eficaz en su tarea legislativa, al no ir acompañada de un mínimo grado de crítica o censura a los articulados. Los procuradores terminaron habituándose a una inveterada costumbre de votar en masa favorablemente a todo lo que el Gobierno les ponía delante, hecho que terminó por hundir su ya de por sí mermada credibilidad.

La unanimidad, de todos modos, no siempre estaba asegurada, a pesar de que la Presidencia tratara por todos los medios de garantizarla. En las Cortes de la dictadura

${ }^{68}$ FERRANDO BADÍA, Juan: El régimen de Franco. Un enfoque político-jurídico, Madrid, Tecnos, 1984, p. 131. 
interesaban las "calidades" además de las "cantidades" de votos, es decir, saber exactamente quiénes eran las personas que negaban o se abstenían ante los deseos del Gobierno y, claro está, de Franco. Llamaba la atención entre los ambientes políticos del régimen que a ciertas leyes se opusieran personalidades relevantes, como sucedió cuando Javier Conde y Rafael Cavestany se manifestaron contra la Ley de Ordenación Universitaria $^{69}$, o cuando Tomás Allende García-Báxter, Rafael García Valiño, Vicente Mortes y Alfonso Peña Boeuf hicieron lo propio contra la Ley de Ordenación de Enseñanzas Técnicas ${ }^{70}$.

A veces, la cantidad, dentro de los niveles propios del franquismo, no era desdeñable. En 1944, con motivo de la aprobación de la Ley de Monopolio de Tabacos ${ }^{71}$, existió un elevado número de votos negativos -cuarenta y cuatro-, en gran medida provenientes de los "sectores corporativos", cultivadores y distribuidores, cuyos intereses en las Cortes chocaron con los del Estado. Algo similar sucedió con la Ley de Ordenación de la Industria Resinera ${ }^{72}$, que tuvo muchos años el récord de votos negativos -setenta y dos- en la Cámara, dado que los industriales se sentían perjudicados en el reparto de los beneficios del negocio frente a los leñadores.

En otras ocasiones, la actuación de las Cortes se dejaba notar en sentido restrictivo y conservador respecto a lo proyectado por el Gobierno. Así sucedió, por ejemplo, con la tramitación del proyecto de Ley de Libertad Religiosa, que quedó notablemente mutilado por las enmiendas presentadas en Comisión por los procuradores. Aunque algunas propuestas no prosperaron, entre otras las que pretendían hablar de la católica como "única religión verdadera" o considerar acto lesivo del orden público la difusión de errores entre los católicos, sí se modificó la mención a que la religión católica era la profesada por "la mayoría del pueblo español", locución sustituida por la expresión "la nación española" "73. Algo parecido sucedió con la Ley de Prensa e Imprenta auspiciada por Manuel Fraga: los procuradores formularon más de 350 propuestas de enmiendas puntuales, que, aun cuando abarcaban todos los artículos, se concentraron en la necesidad

\footnotetext{
${ }^{69}$ BOCE, no 16 , de 15 de julio de 1943, pp. 172-173.

${ }^{70}$ BOCE, no 563 , de 15 de julio de 1957, p. 11.482.

${ }^{71}$ BOCE, no 42, de 16 de marzo de 1944, p. 720.

72 BOCE, $\mathrm{n}^{\circ} 85$, de 15 de marzo de 1945, pp. 1.803-1.811.

${ }^{73}$ LÓPEZ RODRÍGUEZ, Manuel: La España protestante. Crónica de una minoría marginada (1937-1975), Madrid, Sedmay, 1976, p. 164. Un resumen de las principales discusiones en las Cortes en Regulación del ejercicio del derecho civil a la libertad religiosa, Madrid, Ministerio de Justicia, 1968, pp. 11-15; PÉREZ-LLANTADA Y GUTIÉRREZ, Jaime: La libertad religiosa en España y el Vaticano II, Madrid, Instituto de Estudios Políticos, 1974, pp. 297-308, y MORENO SECO, Mónica: "El miedo a la libertad religiosa. Autoridades franquistas, católicos y protestantes ante la Ley de 28 de junio de 1967”, en Anales de Historia Contemporánea, no 17, 2001, pp. 357-358.
} 
de fortalecer la capacidad de intervención administrativa frente a los profesionales de la prensa y las empresas editoras ${ }^{74}$.

Por tanto, más allá de las apariencias institucionales, "la voluntad de Franco era el auténtico órgano legislativo"75. La subestimación del dictador por cualquier función real que las Cortes pudieran ostentar era tal que, en una ocasión, inquirido por uno de sus ministros, Joaquín Ruiz-Giménez, sobre la necesidad de dotar de mayor iniciativa legislativa a la Cámara, Franco le respondió: "¿Pero a quién representan las Cortes?”76. En efecto, el poder de aquella Cámara no derivaba de la aprobación de las leyes, que se encontraba fuertemente mediatizada, sino de que eran "el lugar de encuentro de los poderosos del régimen" ${ }^{77}$. Las Cortes constituyeron, en definitiva, un mosaico de incalculable valor para comprender la variedad de "familias" políticas que habitaban en el seno de la dictadura, representando fielmente el esquema de poder del régimen.

Junto a su participación en las tareas legislativas, correspondía a las Cortes una serie de funciones "solemnes" con las que se pretendía recuperar una práctica de gran arraigo en la tradición monárquica española, consistente en formalizar el mutuo compromiso simbólico entre el monarca y los súbditos y que, al menos en apariencia, implicaba una efectiva limitación del ámbito propio de la Jefatura del Estado. Así, de un lado, las cuestiones relativas a la sucesión en la más alta autoridad del Estado se encontraban reservadas a las Cortes de conformidad con lo dispuesto en la LSJE y en la LOE, si bien el marcado carácter personalista del régimen determinaba que la decisión material correspondiera a Franco; de ahí que, en pura coherencia con esta exigencia, la LOE dispusiera que sus previsiones únicamente serían de aplicación a quienes le sucedieran en la Jefatura del Estado ${ }^{78}$. A partir de este dato debe interpretarse el alcance del resto de los supuestos en que la Ley Orgánica del Estado requería la intervención de las Cortes en relación con el Jefe del Estado, por lo que, al margen del breve lapso durante el cual resultara de aplicación al rey Juan Carlos, podemos concluir que las Cortes tuvieron como

\footnotetext{
${ }^{74}$ Las enmiendas se encuentran depositadas en el $A C D$, serie general, caja 2.312, carpeta 4. Sobre el contenido y proceso de gestación de la ley, vid. CHULIÁ, Elisa: "La Ley de Prensa de 1966. La explicación de un cambio institucional arriesgado y de sus efectos virtuosos", en Historia y Política, no 2, 1999, pp. 197-220.

75 TUSELL, Xavier: La oposición democrática al franquismo, 1939-1962, Barcelona, Planeta, 1977, p. 342.

${ }^{76}$ Cit. en AREILZA, José María de: Diario de un ministro de la Monarquía, Barcelona, Planeta, 1977, p. 73. Poco tiempo antes, ante la afirmación de Franco, en una audiencia, de que las Cortes estaban para controlar al Gobierno, el propio Ruiz-Giménez le replicó que había llegado al convencimiento de que, en España, “únicamente Su Excelencia y él mismo creía que sirvieran para eso". Vid. PÁNIKER, Salvador: Conversaciones en Madrid, Madrid, Kairós, 1969, p. 333.

77 BAENA DEL ALCÁZAR, Mariano: Élites y conjuntos de poder en España (1939-1992). Un estudio comparativo sobre Parlamento, Gobierno y Administración y gran empresa, Madrid, Tecnos, 1999, p. 286.

${ }^{78} \mathrm{LOE}$, disposición transitoria $1^{\mathrm{a}}$.
} 
principal finalidad maquillar el déficit de representatividad de que adolecía la organización pública franquista.

Esta función de apoyo político, aunque no estaba recogida en las leyes, no tenía una menor importancia respecto de las de legislación y fiscalización. Al contrario, era la más conocida de ellas, por cuanto a la opinión pública se le mostraba más evidente. El afán laudatorio de la Cámara se manifestaba permanentemente y se dirigía no solo hacia Franco, sino también hacia sus ministros y todo cuanto significaba defensa a ultranza de los principios ideológicos de la dictadura. El "aplausímetro" de las Cortes, que en los Parlamentos democráticos puede resultar algo protocolario o adjetivo, alcanzó en la democracia orgánica franquista una trascendencia de primer orden. La denominada función "resonadora" hizo sombra a todas las demás y produjo, indirectamente, un daño irreparable en el prestigio de la institución, a la cual el grueso de los españoles nunca reconoció legitimidad ${ }^{79}$.

\section{ORGANIZACIÓN Y FUNCIONAMIENTO}

La autonomía de las Asambleas parlamentarias, consecuencia del poder de organización interna que conserva todo poder constituido, poseía en las Cortes un carácter relativo: la propia naturaleza del régimen político en que se desarrollaban podía considerarse un límite insalvable a la misma. La configuración de sus órganos directivos muestra la falta de independencia de la Cámara. Así, la LC preveía el nombramiento directo de la Mesa de las Cortes, compuesta por el presidente, dos vicepresidentes y cuatro secretarios, por parte del Gobierno, cercenando así una de las autonomías básicas de todo Parlamento. La existencia de la Mesa no debe crear la falsa idea de una dirección colegiada. Al contrario, las más importantes atribuciones corrían a cargo del presidente, que era asistido preferentemente por la Comisión Permanente y no por la Mesa. El presidente de las Cortes realizaba la idea de una Presidencia típicamente unipersonal, rodeada de unos compañeros de Mesa, con carácter más de auténtico jefe que de primus inter pares y, en definitiva, de un director de la Cámara $^{80}$. Tras la aprobación de la LOE, la duración del cargo presidencial se limitó a 6 años y, aunque se confirmó la facultad exclusiva para su nombramiento al Jefe del Estado, se incluyó como requisito previo una propuesta en terna del Consejo del Reino. Esta novedad legislativa, sin embargo, no redujo la discrecionalidad absoluta de Franco para

\footnotetext{
${ }^{79}$ AGUIRRE BELLVER, Joaquín: Por los pasillos de las Cortes, Madrid, G. del Toro, 1972, p. 13.

80 GASCÓN HERNÁNDEZ, Juan: "Caracteres y funciones de la Presidencia de las Cortes Españolas", en Revista de Estudios Políticos, n 19, 1945, p. 144.
} 
elegir a quien le placiese, pues el Consejo del Reino se limitaba a presentar una lista en la que figuraba de antemano el candidato preferido por el "Caudillo".

La posición preeminente del presidente dentro del complejo orgánico de las Cortes se aprecia observando la multitud de atribuciones que reglamentariamente le estaban asignadas: dirigía las sesiones plenarias; las de la Comisión Permanente y las de las demás Comisiones que tuviese a bien; organizaba los "debates"; distribuía a los procuradores en las distintas Comisiones; y coordinaba la labor de las Ponencias ${ }^{81}$. El poder del presidente no se extendía, por tanto, solo a los Plenos, sino al conjunto de las Comisiones, donde podía elegir libremente a sus presidentes, hasta tal punto que ha llegado a sostenerse que éstos últimos solo eran "delegados del presidente de las Cortes" 82 . Aparte de esto, la Presidencia de las Cortes era una de las varias facetas que concurrían dentro de una compleja y rica personalidad política, puesto que aquella cualidad llevaba aparejada la Presidencia del Consejo del Reino, la del Consejo de Regencia y la de la Comisión de Competencia Legislativa. La figura del presidente de las Cortes se convirtió en una de las piezas claves del régimen, en una especie de "representante del conjunto de la clase política" ante Franco que jugaba "un papel muy importante, sin duda más que el de cualquier ministro" ${ }^{\prime 3}$.

Las funciones omnímodas de la Presidencia se vieron potenciadas por la figura del tradicionalista vizcaíno Esteban Bilbao, quien la ocupó entre 1943 y 1965. Bilbao, que arrancó su carrera política acompañando a Vázquez de Mella en sus campañas por el País Vasco $^{84}$, dio al trabajo de la Cámara un perfil de "permanencia y continuismo", de modo que mientras él fue presiente las Cortes, éstas "no dijeron otra cosa que lo que el Gobierno quería" $"$. Entre sus propios compañeros adquirió pronto fama de estar "muy gastado y anticuado", así como el carácter de su oratoria, puesta de manifiesto en cada Pleno, tildada de "elocuencia a báscula" presidiera la etapa de apertura que debía inaugurar la LOE motivó su cese. La elección de su sucesor, Antonio Iturmendi, tuvo un evidente sentido de continuidad, dado que Franco

${ }^{81}$ JERÓNIMO SÁNCHEZ-BEATO, Estefanía y MORALES PAYÁN, Miguel Ángel: De las Cortes Españolas al Congreso de los Diputados: el devenir de su Presidencia (1942-1978), Almería, Universidad de Almería, 1997, p. 47.

82 IGLESIAS SELGAS, Carlos: Las Cortes Españolas. Pasado, presente y futuro, Madrid, Cabal Editor, 1973, p. 218.

83 TUSELL, Javier y GARCÍA QUEIPO DE LLANO, Genoveva: Tiempo de incertidumbre. Carlos Arias Navarro entre el franquismo y la Transición (1973-1976), Barcelona, Crítica, 2003, p. 59.

${ }^{84}$ PELÁEZ ALBENDEA, Manuel J. (ed.): Diccionario crítico de juristas españoles, portugueses y latinoamericanos (bispánicos, brasileños, quebequeses y restantes francófonos), vol. I, Zaragoza-Barcelona, Cometa, 2005, p. 152.

85 FRANCO SALGADO-ARAUJO, Francisco: Mis conversaciones privadas con Franco, Barcelona, Planeta, 1976, p. 99.

${ }^{86}$ PADILLA BOLÍVAR, Antonio: Los hombres de Franco. 161 personajes clave en el franquismo, Barcelona, Flor del Viento, 2008, p. 43. 
consideraba que al frente de la institución más "típicamente tradicionalista" del régimen debía estar un dirigente de esta tendencia. El breve mandato de Iturmendi se prolongó hasta 1969, año en que dimitió aduciendo "motivos de salud", si bien su retirada tuvo que ver, en buena medida, con una cuestión de "postura ética" ante su desacuerdo por la designación de Don Juan Carlos como sucesor de Franco a título de rey ${ }^{87}$.

La sustitución de Iturmendi rompió la línea tradicionalista en la Presidencia de las Cortes. Tras la formación del "Gobierno monocolor" que siguió al "affaire Matesa", Franco se vio obligado a reequilibrar el sistema de contrapesos entre las "familias" políticas que sustentaban al régimen, razón por la que colocó al falangista Alejandro Rodríguez de Valcárcel en la dirección de la Cámara. Con Rodríguez de Valcárcel se pretendía asegurar al frente de las Cortes a un hombre caracterizado por su fidelidad a Franco, más allá de cualquier otra consideración ideológica ${ }^{88}$. Su elección constituía una apuesta de cara a la muerte del dictador para garantizar la lealtad, a través de su Presidencia, de tres instituciones tan básicas en el momento de la sucesión como eran las Cortes, el Consejo del Reino y el Consejo de Regencia. Desde la Presidencia trató, y en cierta medida consiguió, la "bunkerización” de la Cámara, es decir, la conversión de la institución en el último bastión de la ortodoxia frente a un incierto futuro en el que la reforma democrática se planteaba como posible ${ }^{89}$. Sin embargo, la muerte de Franco se produjo antes de que pudiera ejecutarse la renovación automática, por otro sexenio, de su cargo. Indispuesto con el rey Juan Carlos, en diciembre de 1975 Rodríguez de Valcárcel fue cesado y sustituido por Torcuato Fernández-Miranda, que diseñaría la estrategia parlamentaria para transformar las instituciones políticas de la dictadura, sin ruptura legal aparente, mediante la Ley para la Reforma Política (LRP).

Profundizando en la organización de las Cortes, hemos de hacer referencia al sistema de Comisiones, "grupos de reducido número de miembros de la Cámara que por especial encargo suyo estudian ampliamente y en detalle los asuntos para preparar los trabajos del Pleno" ${ }^{90}$. La característica principal de las Comisiones de la Asamblea de la dictadura estribaba en que se constituyeron en el medio habitual de trabajo y eclipsaron

\footnotetext{
87 ÁlVAREZ PUGA, Eduardo, CLEMENTE, José Carlos y GIRONÉS, José Manuel: Los 90 ministros de Franco, $3^{a}$ ed., Barcelona, Dopesa, 1971, p. 168.

88 BARDAVÍO, Joaquín: Políticos para una crisis, Barcelona, Sedmay, 1975, p. 99.

89 MONFORT I COLL, Aram: "Las Cortes franquistas", en Actas del $53^{\circ}$ Congreso de la Comisión Internacional para el Estudio de la Historia de las Instituciones, vol. II, Barcelona, Parlamento de Cataluña, 2005, pp. 1.061-1.062. 90 MARAVALL, José Antonio: Los Reglamentos de las Cámaras legislativas y el sistema de Comisiones, Madrid, Instituto de Estudios Políticos, 1947, p. 66.
} 
completamente a los Plenos, mero "apéndice de la función representativa" ${ }^{11}$ La primera de ellas, y la más importante, era la Comisión Permanente, comandada a su vez por el presidente de las Cortes, cuyas labores fueron decisivas tanto para el régimen interno de la institución como para sus relaciones exteriores, lo mismo con el Gobierno que con la Justicia, pues podía promover recursos de contrafuero sobre disposiciones ministeriales de carácter general o solicitar al Gabinete y a sus componentes información acerca de su gestión.

Con la entrada en vigor de la LOE, la Comisión Permanente se consolidó como una auténtica delegación del Pleno, llamada a representar y hacer valer la voluntad de éste. Estaba formada por el presidente de las Cortes, que la presidía; dos miembros del Gobierno; los presidentes del Consejo Supremo de Justicia Militar, del Tribunal de Cuentas del Reino y del Consejo de Economía Nacional; dos miembros de la Comisión Permanente del Consejo Nacional elegidos por ésta; dos consejeros nacionales elegidos por el Pleno del Consejo Nacional entre sus miembros; dos procuradores elegidos por cada uno de los grupos de representación sindical, local y familiar; uno elegido por los representantes de los Colegios profesionales, y otro por los de nombramiento del Jefe del Estado; y por un secretario de las Cortes, designado por el presidente, que actuaba de secretario de la Comisión ${ }^{92}$. En resumen, la Comisión Permanente, "Olimpo desde donde nunca regresó nadie para contarlo", funcionó en la práctica como un "mecanismo de seguridad y vigilancia" para evitar que los procuradores se dedicaran al "contrabando de ideas"

Las demás Comisiones eran las legislativas o de trabajo, las cuales se correspondían de forma aproximada con los departamentos ministeriales del Gobierno. Tenían a su cargo dictaminar los proyectos y proposiciones de ley en una materia concreta. Las Comisiones de trabajo enumeradas en el RC de 1971 eran las siguientes: Leyes Fundamentales y Presidencia del Gobierno, Asuntos Exteriores, Justicia, Defensa Nacional, Hacienda, Presupuestos, Gobernación, Obras Públicas, Educación y Ciencia, Trabajo, Industria, Agricultura, Comercio, Información y Turismo, y Vivienda ${ }^{94}$. Estaban formadas por los procuradores que, a propuesta de la Comisión Permanente y de acuerdo con el

\footnotetext{
91 MARTÍN OVIEDO, José María: “La representación política en el actual régimen español”, en Revista de Estudios Políticos, n⿳ 198, 1974, p. 236.

92 BOFARULL Y ROMAÑÁ, Manuel de: Las antiguas Cortes, el moderno Parlamento y el régimen representativo orgánico, Alcalá de Henares, 1945, p. 157; FERNÁNDEZ-GENDÍN, Sabino: Las Cortes Españolas, Oviedo, Secretariado de Publicaciones de la Universidad de Oviedo, 1947, p. 60.

${ }^{93}$ DÍAZ-NOSTY, Fernando: Op. cit., pp. 119-121.

${ }^{4}$ Hasta 1958, no existieron las de Información y Turismo, Vivienda y Leyes Fundamentales y Presidencia del Gobierno, las Comisiones de Industria y Comercio estaban unidas en una sola, y la de Asuntos Exteriores se llamaba de Tratados. En 1966, la Comisión de Educación Nacional pasó a llamarse de Educación y Ciencia. En el año 1973 se creó la de Planificación del Desarrollo. Vid. RC de 1971, art. 32.
} 
Gobierno, nombrara el presidente de las Cortes, sin que pudiera exceder de 60 ni bajar de 40 el número de los que componían cada Comisión, salvo la de Presupuestos, que se integraba por 60 miembros. Por otro lado se encontraban las Comisiones generales: la de Régimen Interior, la de Competencia Legislativa, la de Corrección de Estilo y la de Reglamento, todas ellas con funciones auxiliares destinadas a determinar qué materias debían revestir forma de ley o mantener a punto la normativa interna de la Cámara. El sistema de Comisiones se completaba con las especiales, cuya formulación respondía bien a la exigencia de proyectos que por su carácter rebasaran la competencia de una Comisión concreta, bien a la necesidad de llevar a cabo cometidos no legislativos, tales como realizar estudios, practicar informaciones y formular peticiones o propuestas.

Las nutridas competencias de las Comisiones relegaron a los Plenos a "una función de registro público y de notificación solemne al país, tanto de la ley aprobada como de sus fundamentos, expuestos por el presidente o un miembro de la Comisión y, frecuentemente, por un ministro del Gobierno" "95. La forma en que se desarrollaron las sesiones plenarias fue una de las mayores limitaciones de que adolecieron las Cortes. Bajo el impacto del modo en que habían funcionado durante la Restauración y la II República, y por las prevenciones ideológicas con que se contemplaron por quienes tuvieron a su cargo las funciones directivas más caracterizadas, no llegaron nunca a desarrollarse en su integridad. Los Plenos, que en los regímenes democráticos revisten el mayor interés por cuanto tienen un carácter social y favorecen los contactos de la clase política, quedaron reducidos a reconocer las decisiones de las Comisiones, perdiendo las Cortes su carácter de Asamblea deliberante. Esa situación destruía la unidad de la Cámara como Cuerpo legislativo, ya que todo el trabajo se realizaba separadamente en las Comisiones y de ellas venía acordado el dictamen que iba a prosperar.

El número real de sesiones plenarias marca el lugar efectivo de la Asamblea en el seno de las instituciones de un Estado; solo cuando la cifra anual ronda el centenar, como era el caso de Gran Bretaña, Italia, Estados Unidos, Francia o los Países Bajos, puede hablarse de "actividad parlamentaria normal"". En España, el Pleno de las Cortes se reunió un máximo de 10 sesiones al año (en 1971) y un mínimo de 3 (en 1958) ${ }^{97}$. Fracasaron todas las tentativas por vitalizar los Plenos: tanto los intentos de crear períodos de sesiones estables como la posibilidad de habilitar fórmulas para adelantar la lectura de los proyectos

95 SÁNCHEZ AGESTA, Luis: "Cortes", en Nueva Enciclopedia Jurídica, tomo V, Barcelona, Francisco Seix Editor, 1953, p. 835.

${ }^{96}$ Parlements, $2^{\mathrm{a}}$ ed., Paris, Union Interparlementaire-Presses Universitaires de France, 1966, p. 146.

97 GÓMEZ DE LA SERNA, Gaspar: Las Cortes Españolas, Madrid, Comisión de Gobierno Interior de las Cortes-Sucesores de Rivadeneyra, 1971, p. 85; FRAILE CLIVILLÉS, Manuel María: Op. cit., p. 232. 
por un Pleno reunido de forma informal fueron sistemáticamente vetados por el Gobierno. $\mathrm{Y}$ es que el Ejecutivo obró siempre en este punto tratando de proteger sus intereses, garantizando la total docilidad de los Plenos mediante la prohibición de los debates. Los procuradores, de hecho, ni siquiera podían intervenir en las sesiones desde su propio escaño, sino que debían utilizar obligatoriamente la tribuna. Tampoco había posibilidad de que un miembro de la Cámara solicitara la palabra si en el orden del día, acordado de antemano entre el Gobierno y el presidente de las Cortes, no estaba prevista su intervención. No es de extrañar que algunos afirmaran que los Plenos eran un lugar donde "no se habla: se oye" $"$.

Al estar proscritos los partidos políticos, los procuradores actuaban de forma individual y, por tanto, poco organizada. La autorización de los grupos parlamentarios no se produjo hasta fecha muy tardía, marzo de 1976, y el contexto en el que se produjo la misma se enmarcó ya dentro del proceso de transición a la democracia. Con la formación de los grupos se pretendía preparar a los procuradores para la reforma que estaba por venir. Fernández-Miranda, presidente de las Cortes, fue el impulsor de la medida, que tenía más que ver con el "divide y vencerás" que con cualquier otro planteamiento de altura política. Partiendo del hecho de que la Cámara no era un bloque monolítico, sino que en su seno coexistían "corrientes quietistas y corrientes dinámicas", con esta medida se fortaleció la autonomía de los procuradores para que pudieran hacer oír su voz, de forma organizada y por lo tanto más efectiva, frente a los sectores inmovilistas que mantenían bajo su control el funcionamiento de la Cámara. Contra la opinión generalizada de que las Cortes eran un obstáculo insalvable para el cambio, lo que Fernández-Miranda pretendía era integrarlas en la reforma. Así, por ejemplo, ante la afirmación de Fraga, en la Comisión de Gobernación, de que "la vida española no tolera de las instituciones otra respuesta que la adaptación o la muerte", el presidente de las Cortes respondió que había "una tercera vía, la modificación del medio; ésta no admite vanas ilusiones pero evita el abandonismo",99.

La medida fue bien acogida por los sectores reformistas, que no se engañaron sobre la finalidad de la misma: no era un intento de dotar de nueva vida a las Cortes, sino de romper el gregarismo imperante entre sus miembros. Así, el letrado mayor adjunto de la Cámara, Manuel Fraile Clivillés, afirmó que con la medida por primera vez las Cortes “iban a empezar a parecerse a un Parlamento europeo" y que ya nadie iba a hablar "a título personal, sino en función de un grupo que le va a respaldar". La opinión pública sabría

\footnotetext{
98 ROMERO, Emilio: Op. cit., p. 69.

${ }^{9}$ FERNÁNDEZ-MIRANDA LOZANA, Pilar y FERNÁNDEZ-MIRANDA CAMPOAMOR, Alfonso: Lo que el Rey me ha pedido. Torcuato Fernández-Miranda y la reforma política, Barcelona, Plaza \& Janés, 1995, p. 134.
} 
ahora "a qué atenerse y por dónde van los tiros", porque "precisamente los partidos políticos nacen como consecuencia del agrupamiento de parlamentarios frente a la competición electoral" ${ }^{100}$. Los grupos parlamentarios comenzaron a formarse antes incluso de que se dictase la disposición que permitía su creación, porque la Comisión de Reglamento manifestó a los procuradores que tal posibilidad iba a hacerse realidad de forma inminente. Debían contar al menos con 50 procuradores en su seno, si bien la Presidencia permitió en la práctica la formación de grupos con, al menos, 25 miembros ${ }^{101}$.

De entre los 6 que se establecieron, el más cercano al "búnker" fue el de Acción Institucional, partidario de la continuidad con el régimen, que integraba a falangistas y tradicionalistas históricos como Raimundo Fernández-Cuesta, Pilar Primo de Rivera, Antonio María de Oriol o José Luis Zamanillo. Otros tres grupos, Unión del Pueblo Español, el Laboral-Democrático y el Regionalista agrupaban a diferentes sectores de la derecha franquista sensibles a una apertura política, que permitiera la renovación del régimen representativo para hacerlo "políticamente auténtico, dentro de las Leyes Fundamentales y de los principios ideológicos del Movimiento Nacional”. Por su parte, Unión Democrática Española reunió a los procuradores pertenecientes a la asociación política homónima de inspiración católica que dirigía Alfonso Osorio. Atenazado por las disensiones internas, el sector más derechista del grupo, siguiendo a Federico Silva y Alberto Monreal, terminó escindiéndose. El nacimiento de Alianza Popular (AP) provocó el reagrupamiento de estos grupos parlamentarios. Los promotores de la coalición franquista acabaron por organizar una coordinadora que coaligaba los grupos de Unión del Pueblo Español, Laboral-Democrático, Acción Institucional y Regionalista, así como los escindidos con Silva y Monreal de la Unión Democrática Española. AP consiguió así reunir a 183 procuradores, lo que constituía algo más del 30\% del total de la Cámara. El único grupo de talante claramente reformista fue el Independiente, en virtud del cual terminaría trabajando posteriormente con el Gobierno Suárez. De hecho, resultó ser en el futuro una importante cantera de dirigentes para Unión de Centro Democrático (UCD), como Gabriel Cisneros, Josep Melià o Enrique Sánchez de León ${ }^{102}$.

\footnotetext{
${ }^{100}$ FRAILE CLIVILLÉS, Manuel María: "No merma derechos", en Ya, 8 de febrero de 1976. 101 BOCE, $\mathrm{n}^{\circ} 1.489$, de 9 de marzo de 1976, p. 35.989.

$102 A C D$, serie general, caja 3.691, carpetas 1-6.
} 


\section{EL “HARAQUIRI”}

La formación de los grupos parlamentarios no fue suficiente para una efectiva transformación de una Cámara que representaba las posturas más intransigentes respecto a cualquier opción de evolución transformadora del sistema. A diferencia de los dictámenes del Consejo Nacional, que no eran vinculantes, el beneplácito de las Cortes era imprescindible para cualquier proyecto de reforma de las Leyes Fundamentales que quisiera llevarse a término, por lo que el Gobierno no podía recurrir a disolverlas o ignorar sus resoluciones. En efecto, con arreglo a la legalidad vigente, el Ejecutivo no podía disolver las Cortes y proceder a convocar elecciones por sufragio universal sin modificar la LC, que establecía los cauces orgánicos ${ }^{103}$. Y, a su vez, tal cambio “constitucional” no podía hacerlo el Ejecutivo por sí mismo mediante decreto-ley y sin intervención de las Cortes, ya que, y en esto las Leyes Fundamentales eran terminantes, para la reforma o derogación de cualquiera de ellas era necesario, como ya apuntamos, el acuerdo de la Cámara y el referéndum preceptivo de la nación ${ }^{104}$. El resultado era que el respeto a la legalidad conducía al Gobierno a un círculo vicioso: para convocar nuevas Cortes por sufragio universal necesitaba una previa reforma de las Leyes Fundamentales, pero para acometerla precisaba, igualmente, unas Cortes orgánicas que no podía disolver.

$\mathrm{Ni}$ siquiera la aplicación de medidas excepcionales en base a la LOE era admisible ${ }^{105}$. Primero, porque una reforma "constitucional" por ese camino habría vulnerado el aludido artículo 10 de la LSJE. Y segundo, porque el contenido de una reforma constitucional nunca podía entenderse como "excepcional", sino todo lo contrario, esto es, como lo que se deseaba que rigiera en el futuro como "normal". Y es que si las Cortes franquistas se negaban a la reforma, ya no solo estaría en peligro el sistema institucional del régimen por ese enfrentamiento entre órganos imprevisto en la "coordinación de funciones" consagrada por la LOE, sino que la situación rebasaría con mucho el grado de gravedad "constitucional" para convertirse en crítica, al demostrar a las claras la ilegitimidad de un sistema incapaz de reformarse a sí mismo ${ }^{106}$.

\footnotetext{
103 LC, art. 2.

104 LSJE, art. 10.

${ }^{105}$ LOE, art. 10, d.

106 ÁGUILA, Rafael del: "La dinámica de la legitimidad en el discurso político de la transición”, en Ramón COTARELO (comp.), Transición política y consolidación democrática. España (1975-1986), Madrid, Centro de Investigaciones Sociológicas, 1992, pp. 47-75.
} 
Que la actitud de las Cortes podía dinamitar todo intento de cambio en sentido democrático quedó patente cuando, en junio de 1976, el Gobierno Arias sometió a la Cámara la reforma de los artículos 172 y 173 del Código Penal, que ilegalizaban los partidos políticos. Condicionados por sus tradicionales fantasmas, la principal obsesión de la mayoría de los procuradores era la de cerrar el paso a cualquier posibilidad de legalización del Partido Comunista de España (PCE) y el espectro situado a su izquierda. El "búnker" se encastilló en esa intransigencia y consiguió que el Gobierno incluyera una fórmula que impedía declarar lícitas a aquellas organizaciones que, "sometidas a una disciplina internacional”, se propusieran "implantar un sistema totalitario". El titubeante discurso del ministro de Justicia, Antonio Garrigues, encendió los ánimos de muchos procuradores, que amenazaron con votar en contra del proyecto de ley del Gobierno. Carlos Arias, temeroso de que si forzaba la votación la perdería, decidió retirar su discusión en el Pleno ${ }^{107}$, precipitando así la crisis ministerial que desembocaría en su dimisión.

El nuevo presidente del Gobierno decidió cambiar de táctica. Consciente de que una parte de la clase política del régimen, atrincherada en las Cortes, no estaba dispuesta a dejarse arrebatar el monopolio del poder que hasta entonces había detentado, Adolfo Suárez se centró en convencer a los procuradores continuistas, que dominaban en las Cortes, de que aprobaran alguna fórmula de cambio gradual hacia la democracia. El trabajo de Suárez consistió, principalmente, en maniobrar, prometer, embarullar, seducir, "pasillear" y, en definitiva, convencer a los hombres instalados en los escaños de la Cámara de que la reforma era necesaria y de que, en realidad, las cosas no se iban a trastocar demasiado. Tenía que trasladar al ánimo de los procuradores que el sufragio universal no era algo a temer, sino un sistema que los legitimaría a través del pueblo. Porque, "naturalmente", no tenían enemigo y la gran mayoría seguiría en el primer plano del $\operatorname{poder}^{108}$.

De todos modos, resultaba evidente que la Ley para la Reforma Política, la herramienta jurídica clave en la estrategia de reforma democrática que, al tratarse de una Ley Fundamental, las Cortes debían aprobar por dos tercios de sus miembros, suponía la liquidación de la dictadura a través de sus propios mecanismos legales. Si la Cámara decía "sî" a la LRP negaba sus 35 años de existencia, enterraba la democracia orgánica y reconocía que el régimen liberal era, en contra de lo que tanto tiempo habían venido defendiendo, lo conveniente para el futuro de España. Al objeto de evitar la obstrucción de

${ }_{107}$ BOCE, Diario de las Sesiones del Pleno (DSP), no 27, de 8 y 9 de junio de 1976, pp. 143-145.

108 MÍGUEZ GONZÁLEZ, Santiago: La preparación de la transición a la democracia en España, Zaragoza, Universidad de Zaragoza, 1990, p. 206. 
los más inmovilistas, Fernández-Miranda acordó con Suárez que la LRP se tramitara por el "procedimiento de urgencia", que evitaba el paso del proyecto por la Comisión de Leyes Fundamentales y Presidencia del Gobierno, donde estaba la "guardia pretoriana del franquismo, el búnker del búnker" ${ }^{109}$, y lo confiaba a una Ponencia directamente designada por la Presidencia de las Cortes, limitando el tiempo de enviar enmiendas. El informe de la Ponencia podía recoger aquellas que estimase convenientes, votándose sobre el proyecto en conjunto, lo que daba escasas posibilidades a aquellos que hubiesen presentado alguna modificación al texto no aceptada por la Ponencia ${ }^{110}$.

Los debates en el Pleno se celebraron el 16, 17 y 18 de noviembre de 1976, días que han sido calificados como "los más decisivos en la transición española" de la Ponencia fue defendido por Miguel Primo de Rivera, sobrino del fundador de Falange y amigo personal del rey, que fue nombrado por Fernández-Miranda para apaciguar los ánimos de los continuistas. En su intervención sostuvo que el objetivo de la LRP era "hacer una nueva Constitución basada en la legalidad de la Constitución vigente", es decir, engarzando pasado y futuro, lo que requería la participación de los españoles a través del sufragio. Se trataba de "pasar de un régimen personal a un régimen de participación, sin rupturas y sin violencias, pero con esa nueva y clara legitimidad política que el soberano pueblo español proclame con su libre expresión" ${ }^{112}$.

Se presentaron 3 enmiendas a la totalidad y 20 parciales. Entre las primeras destaca la de Blas Piñar, quien afirmó que el "proyecto de reforma se halla en conflicto con la filosofía política del Estado que surgió de la Cruzada", y si bien declaraba no ser enemigo de los cambios, sí lo era del que presentaba el Gobierno, pues "no es de verdad una reforma, es una ruptura". Junto a argumentos políticos y jurídicos, insistía principalmente en los de naturaleza moral al referirse a la fidelidad debida a la Ley de Principios del Movimiento Nacional (LPMN), que por su propia esencia era inmutable. Otro de los enmendantes, José María Fernández de la Vega, recordaba que el juramento sobre la LPMN también lo había realizado el rey Juan Carlos ${ }^{113}$. Por último, Blas Piñar rechazaba "componendas, pasteleos y ficciones", y confesaba preferible "un período constituyente abierto con todas sus consecuencias, que esta mascarada estúpida de reforma democrática" ${ }^{\text {114 }}$. La contestación de la Ponencia a las enmiendas a la totalidad correspondió

\footnotetext{
${ }^{109}$ FERRANDO BADÍA, Juan: Del autoritarismo a la democracia, Madrid, Rialp, 1987, p. 124.

${ }^{110}$ BOCE, no 1.499, de 23 de abril de 1976, pp. 36.317-36.319.

${ }^{111}$ SOTO CARMONA, Álvaro: “De las Cortes orgánicas...”, op. cit., p. 117.

112 BOCE, DSP, n ${ }^{\circ} 29$, de 16, 17 y 18 de noviembre de 1976, pp. 5-11.

113 Ibidem, p. 21.

${ }^{114}$ Ibidem, pp. 32-40.
} 
al ex ministro de Trabajo, Fernando Suárez, el cual reconoció en su intervención que la reforma pretendía modificar "algunos preceptos de nuestro actual ordenamiento constitucional", e insistió en la posibilidad de modificar los Principios del Movimiento por la decisión de los ciudadanos, ya que en último término correspondía "a los españoles la posibilidad de decidir su futuro" 115 .

Por lo que se refiere a las enmiendas y sugerencias de los demás procuradores, los temas fueron muy variados, reflejando la pluralidad de intereses que había en las Cortes. Así, hubo desde recelos por el fin de la representación orgánica, hasta peticiones de que se mantuviera una sola Cámara, pasando por la defensa de los intereses territoriales. De todos modos, aunque las palabras de los inmovilistas caldearon el ambiente, ninguna de ellas supuso una amenaza real porque no estaban respaldadas por un número de procuradores lo bastante amplio como para que pudieran peligrar esos dos tercios de votos necesarios para sacar adelante la LRP. El verdadero peligro vendría con la negociación de la ley electoral. Así, la presión de los grupos parlamentarios integrados en AP sobre el Gobierno, concretada en la enmienda defendida por Cruz Martínez Esteruelas, hizo temer que los procuradores de dichos grupos se abstendrían, lo que hubiese supuesto un fuerte revés político. Finalmente, se llegó a un acuerdo según el cual el Gobierno se comprometía a redactar una normativa electoral que primara la proporcionalidad en el reparto de escaños, pero con dispositivos correctores que lo convertirían, de hecho, en un sistema mayoritario. En virtud de este pacto, se consideraba a la provincia como circunscripción electoral, y se fijaba un mínimo, tanto de diputados como de porcentaje de votos, para acceder al Congreso. AP pensaba que dicho sistema le daría la mayoría absoluta en las Cámaras ${ }^{116}$.

La última intervención correspondió al ministro de Justicia, Landelino Lavilla, que exhortó a los procuradores a votar la reforma, la cual no estaba hecha "contra nada ni contra nadie", sino apelando "a una decisión última del pueblo español en la línea de nuestra mejor tradición" para que "nadie hable en nombre del pueblo que no ha hablado, ni se arrogue representaciones si no las ha recibido" ${ }^{117}$. A continuación se procedió a la votación, cuyos resultados supusieron un claro triunfo del Gobierno: de un total de 497 procuradores presentes votaron afirmativamente $425^{118}$. Los 59 votos negativos y las 13 abstenciones provinieron del sector ultraderechista de la Cámara, 8 de ellos generales en

\footnotetext{
115 Ibidem, pp. 24-32.

116 LÓPEZ NIETO, Lourdes: Alianza Popular. Estructura y evolución legal de un partido conservador (1976-1982), Madrid, Siglo XXI-Centro de Investigaciones Sociológicas, 1988, p. 21.

117 BOCE, DSP, no 29, de 16, 17 y 18 de noviembre de 1976, pp. 193-198.

118 Ibídem, pp. 198-203.
} 
situación de retiro ${ }^{119}$. El resultado estaba cuidadosamente calculado. A 15 procuradores, encabezados por Alberto García Ortiz, el Gobierno les mandó de viaje oficial a Panamá con escala en Cuba, como parte de una delegación sindical ${ }^{120}$; y hasta Miguel Primo de Rivera convenció a su tía Pilar de que al menos se abstuviera, ya que su conciencia política le impedía votar a favor de la ley ${ }^{121}$. La reacción de los procuradores al aprobar la LRP fue bastante sorprendente: celebraron su muerte política con una cerrada ovación. En todo caso, el "haraquiri” de las Cortes puso fin a "esa dedocracia insigne que nunca creyó en sus propios principios", si bien a sus miembros les cupo "la grandeza histórica" de crear algo que desde entonces "los tratados de ciencia política" deberían describir: "la inverosímil historia de una dictadura que se convirtió a sí misma en un régimen de libertad” ${ }^{\text {"122. }}$.

¿Por qué esta inmolación política de los procuradores franquistas? Es imposible dar una respuesta unívoca. Un cúmulo de razones explica este final autoimpuesto. En primer término, cabe hablar del hábito de obediencia. Los miembros de las Cortes nunca habían votado en contra, como ya dijimos, de ningún proyecto de ley enviado por el Ejecutivo. La arraigada costumbre de acatar lo que venía "de la autoridad" y la ausencia de una auténtica labor autónoma, tantos años favorable a los Gobiernos de Franco, terminaron volviéndose contra el régimen ${ }^{123}$. Ello no debe hacernos olvidar la labor de "convencimiento personal" desplegada frente a cada uno de los reticentes procuradores de que tenían que apoyar la LRP ${ }^{124}$. Los distintos ministros se repartieron la tarea según la afinidad de las áreas de su competencia, si bien la coordinación del trabajo corrió a cargo del vicepresidente Alfonso Osorio. En general, casi todos ellos se mostraron, en un principio, contrarios a la reforma. Para disuadirles se les adujeron argumentos catastrofistas ("no hagamos que un régimen que comenzó con una Guerra Civil acabe con otra"), nostálgicos ("Franco se hubiera adaptado a los tiempos”), demagógicos (“el pueblo está con nosotros, dejemos que hable”), jurídicos ("nuestras leyes siguen ahî"), disciplinarios (“es lo que quiere el rey”) y hasta cínicos (“es la única manera de seguir donde estamos”)"

\footnotetext{
119 ESTEBAN, Jorge de y LÓPEZ GUERRA, Luis: De la Dictadura a la Democracia. (Diario político de un periodo constituyente), Madrid, Universidad Complutense, 1979, p. 139.

120 YSART, Federico: Quién hizo el cambio, Barcelona, Argos Vergara, 1984, p. 112.

121 ABELLA, Carlos: Adolfo Suárez, Madrid, Espasa, 1997, p. 122.

122 “Ganó el país”, en Diario 16, de 19 de noviembre de 1976.

123 SÁNCHEZ NAVARRO, Ángel J.: La transición politica en las Cortes de Franco: hacia la Ley para la Reforma Politica, Madrid, Instituto Juan March, 1990, pp. 22-23.

124 MARTÍN VILLA, Rodolfo: Al servicio del Estado, Barcelona, Planeta, 1985, p. 53.

125 OSORIO, Alfonso: Trayectoria política de un ministro de la Corona, Barcelona, Planeta, 1980, pp. 230-246.
} 
A los más recalcitrantes se les prometió un escaño en el futuro Senado o puestos en Consejos de Administración de empresas públicas. Además, Suárez hizo mucho hincapié en que el Congreso y el Senado democráticos juntos tendrían el mismo número de escaños que las Cortes franquistas, lo cual influyó en muchos procuradores que habían llegado a creer que verdaderamente eran populares y representaban a sus respectivas demarcaciones. Suponían, por ello, que simplemente serían reelegidos por sus agradecidos electores o que Suárez lo "arreglaría" de alguna manera ${ }^{126}$. Lo cierto es que la mayoría de ellos jamás volvería a pisar el Palacio de la Carrera de San Jerónimo: de todos procuradores que pasaron por las Cortes ${ }^{127}$, solo 101 consiguieron un acta de diputado o de senador en las sucesivas Cortes democráticas. Aunque la mayoría de ellos se encuadraron en los grupos parlamentarios de UCD o de AP, se dieron casos de antiguos procuradores que terminaron "reciclándose" para engrosar las filas de formaciones socialistas e, incluso, nacionalistas o regionalistas ${ }^{128}$.

Pero no hay que acudir necesariamente a la corrupción y la bajeza moral para la aprobación por las Cortes de la LRP. Entender el insólito "haraquiri" de la institución requiere tener en cuenta otros factores. En primer lugar, el papel moderador del rey, es decir, el decidido apoyo de Don Juan Carlos hacia el proyecto, que influía sobre una mayoría de procuradores que habían prestado lealtad al monarca. Por otro lado, el convencimiento de la propia clase política franquista de que su papel estaba acabado; así como el apoyo internacional al proyecto gubernamental, especialmente de los Gobiernos de la República Federal de Alemania y de los Estados Unidos. Sin obviar, finalmente, la presión generalizada y creciente de la opinión pública, que podía detectarse en la prensa ${ }^{129}$. Otros analistas han apuntado recientemente la idea de un proceso de coordinación de expectativas. Así, en un contexto marcado por la incertidumbre, para muchos procuradores habría sido importante no quedar en una posición minoritaria o marginal, de forma tal que muchos de ellos se limitó a observar a sus compañeros y votar a favor del "viento de la historia" ${ }^{130}$. En cualquier caso, la cautela e imaginación del Gobierno Suárez al proponer la LRP como el modo de asumir la historia y abrirse al futuro democrático sobre la base de la "reconciliación nacional" hizo que la reforma apareciera ligada a una revisión ideológica de las propias Cortes orgánicas, de forma que no se hizo evidente a sus miembros el auténtico

\footnotetext{
126 PRESTON, Paul: Juan Carlos. El rey de un pueblo, Barcelona, Plaza \& Janés, 2003, p. 414.

127 MAESTRE ROSA, Julio: Procuradores en Cortes, 1943-1976, Madrid, Tecnos, 1977, p. 118.

128 GIMÉNEZ MARTÍNEZ, Miguel Ángel: Op. cit., p. 333.

${ }^{129}$ MORODO, Raúl: La transición política, Madrid, Tecnos, 1984, p. 110.

130 SÁNCHEZ-CUENCA, Ignacio: Atado y mal atado. El suicidio institucional del franquismo y el surgimiento de la democracia, Madrid, Alianza, 2014, p. 255.
} 
alcance del "suicidio institucional" que provocó su voto a favor del proyecto ${ }^{131}$. No hay que olvidar, por último, la objetivización del espíritu de la LRP, más allá de las opiniones concretas de quienes cooperaron en su elaboración, y que después fue sometida a referéndum popular y ratificada por él. Así pues, las Cortes antepusieron la actitud crítica o revisionista a la simple opinabilidad ideológica; pero no podrá decirse "ni que la Ley para la Reforma Política fue obra exclusiva de ellas, ni que ellas consumaron el holocausto" ${ }^{\text {132. }}$.

131 PALACIO ATARD, Vicente: Juan Carlos I y el advenimiento de la democracia, Madrid, Real Academia de la Historia/Espasa Calpe, 1988, p. 108.

132 HERNÁNDEZ GIL, Antonio: El cambio político español y la Constitución española, Barcelona, Planeta, 1981, p. 138. 